\title{
Hydrothermal Dissolution of Deeply Buried Cambrian Dolomite Rocks and Porosity Generation: Integrated with Geological Studies and Reactive Transport Modeling in the Tarim Basin, China
}

\author{
Wenwen Wei, ${ }^{1,2}$ Daizhao Chen, ${ }^{1,2}$ Hairuo Qing, ${ }^{3}$ and Yixiong Qian ${ }^{4}$ \\ ${ }^{1}$ Key Laboratory of Petroleum Resources Research, Institute of Geology and Geophysics, Chinese Academy of Sciences, \\ Beijing 100029, China \\ ${ }^{2}$ University of Chinese Academy of Sciences, No. 19A Yuquan Road, Beijing 100049, China \\ ${ }^{3}$ Department of Geology, University of Regina, Regina, SK, Canada S4S OA2 \\ ${ }^{4}$ Wuxi Research Institute of Petroleum Geology, SINOPEC, Wuxi 214151, China
}

Correspondence should be addressed to Daizhao Chen; dzh-chen@mail.iggcas.ac.cn

Received 12 January 2017; Accepted 20 March 2017; Published 4 May 2017

Academic Editor: Keyu Liu

Copyright (C) 2017 Wenwen Wei et al. This is an open access article distributed under the Creative Commons Attribution License, which permits unrestricted use, distribution, and reproduction in any medium, provided the original work is properly cited.

\begin{abstract}
The burial dissolution of carbonate rocks has long been an interesting topic of reservoir geologists. Integrated with geological studies and reactive transport modeling, this study investigated the Cambrian dolomites that were buried at depths up to $8408 \mathrm{~m}$ and still preserved a large amount of unfilled dissolution vugs from the borehole TS1 in the northern Tarim Basin. Studies indicate that these vugs were formed in association with fault-channeled hydrothermal fluids from greater depth through "retrograde dissolution" as the fluid temperature dropped during upward migration. The reactive transport modeling results suggest an important control of the vertical permeability of wall-rock on fluid and temperature patterns which, in turn, would control the spatial distribution of dissolving-originated porosity. The hydrothermal dissolution mainly occurred in dolomite wall-rocks with higher vertical permeability (extensive development of tensional fractures and connected pore spaces), producing additional dissolved porosity there during deep burial. This study implicates the importance of multidisciplinary approaches for understanding the burial/hydrothermal dissolution of dolomite rocks and predicting favourable deep/ultradeep carbonate reservoirs.
\end{abstract}

\section{Introduction}

It is commonly believed that about $50-60 \%$ of oil and gas reservoirs in the world occur in carbonate rocks [1]. Carbonate reservoirs are commonly heterogeneous as a result of complicated diagenetic processes which could have substantially modified the pore systems [2]. For this reason, understanding of spatial diagenetic differences and subsequent predicting of "sweet" reservoirs are quite a challenge for recovery of carbonate hydrocarbon resources.

The porosity in carbonate reservoirs usually decreases with increasing burial depth due to mechanical-chemical compaction and subsequent cementation $[3,4]$. According to
Schmoker and Halley [3], most petroleum producing reservoirs are buried at depths less than $6000 \mathrm{~m}$ subsurface. However, the borehole TS1, one of the deepest petroleum wells (to the depth of $8408 \mathrm{~m}$ ) in the world, was drilled in the northern uplift of the Tarim Basin, northwestern China, and revealed a large number of dissolution pores and vugs, notably a downward increase in porosity, in the deeply buried Cambrian dolomites from 6884 to $8408 \mathrm{~m}$ deep [5]. Therefore, modeling the fluid property, pathway, and dissolution/precipitation is of great significance in understanding the formation of vuggy pore systems and controls in such a great depth, facilitating exploration for the ultradeep hydrocarbon reservoirs which were poorly constrained and understood in general. 
In recent years, reactive transport modeling (RTM) has become an important tool for understanding the diagenetic process and predicting their spatial patterns [6-8]. RTM couples mineral reactions with groundwater flow, heat, and solute transport [9]. Previous applications of reactive transport models have gained a better insight into dolomitization process $[7,10]$. Based on reactive transport modeling, Lu and Cantrell [11] predicted the dolomite pattern that agrees with observed distribution of dolomites. RMT has also been successfully applied for prediction of reservoir quality in different geologic settings $[8,12,13]$.

Fault-related hydrothermal alteration of carbonate rocks, especially dolomitization, was a very important mechanism controlling the reservoir development [14-16]. However, rare numerical simulations have been carried out to investigate the hydrothermal alteration (or dolomitization) on carbonate reservoirs developed in the fault systems [8]. To improve our understanding of diagenetic process and reservoir development through numerical simulations, a solid study on the geological setting and processes was the basis on which the reservoir model is better refined and established. However, many numerical simulations did not pay enough attention to the geological setting and processes, limiting their application for the complex geological realities.

In this study, we investigated the diagenetic processes and porosity development tied to fault-controlled hydrothermal fluids in the deep Cambrian dolomite reservoir revealed in the ultradeep borehole TS1 ( 8408 m deep) in Tarim Basin, based on the petrographic investigation, petrophysical data integrated with fluid reactive transport modeling using TOUGHREACT V2 [9]. Our reactive transport modeling focused on the critical diagenetic processes and their roles in pore generation and plugging. This would improve our understanding for diagenetic processes and porosity generation/reduction, facilitating prediction for the deep carbonate (dolomite) reservoirs.

\section{Geologic Setting}

2.1. Depositional Setting and Stratigraphy. The Tarim Basin, one of the biggest hydrocarbon-producing basins (with an area of $530,000 \mathrm{~km}^{2}$ ) in China, is located in the northwestern China (Figure 1). From the Cambrian to Middle Ordovician, a thick carbonate succession, up to $2000 \mathrm{~m}$ thick, was deposited in northern Tarim Basin (Figures 2 and 3). A summary of stratigraphic units and their main lithologies in platform interior of Cambrian and Ordovician is illustrated in Figure 2, and relevant information can also be found in $[17,18]$. In ascending order, the Lower Cambrian includes the Yurtus, Xiaoerbulake, and Wusonger formations. Of these, the Yurtus Formation is characterized by the bedded chert, black shale in the lower part, and argillaceous dolomite in the upper part. The Xiaoerbulake Formation is characterized by banded lenticular-like dolomite in the lower part and banded to thin-bedded dolomite intercalated with microbialite in the upper part. The Wusonger Formation is characterized by argillaceous dolomite intercalated with thin- to medium-bedded dolomite. The Middle Cambrian includes the Shayilike and Arwatage formations; they are characterized by variable stromatolites and reddish dolomitic mudrock (or argillaceous dolomite) intercalated with subordinate evaporites. The Upper Cambrian includes the Lower Qiulitage Group, is characterized by cyclic peritidal facies (thrombolite, stromatolite, and laminite) in the lower part and oolites/grainstones with minor microbialites in the upper part. Toward the platform margin where the borehole TS1 is located, the equivalent strata are dominated by massive microbial reefs (or buildups) which initially occur from the middle Xiaoerbulake Formation (Figure 3).

In the northern Tarim Basin, a ramp carbonate platform was built on the antecedent (Neoproterozoic) palaeohigh during the Early Cambrian [19]; it then evolved into a carbonate platform rimmed with microbial buildups and sandy shoals from the late Early Cambrian and further evolved into sandy shoal-protected platform system from the late Late Cambrian to the Early Ordovician (Figures 1(b) and 3). From the Late Ordovician, the carbonate depositional system gradually evolved into a mixed carbonate-siliciclastic system and finally was replaced by a complete siliciclastic system near the end of Ordovician, due to the progressive long-term marine regression in response to the tectonic inversion to a convergent continental margin $[20,21]$.

2.2. Burial History and Tectonic Evolution. Seven tectonic units were identified in the Tarim Basin by previous extensive seismic investigations, including three topographic uplifts (the North, Central, and South uplifts) and four depressions (the Kuche, North, Southwest, and Southeast depressions) (Figure 1(a); [22]). All these had experienced multiple deformations after the burial in response to multiple tectonic movements during the Caledonian, Hercynian, Yanshanian, and Himalayan orogenic episodes (Figure 4(a)).

The study area is located in the North Uplift which was mainly activated during the Caledonian to Hercynian phases. The burial history for the Cambrian to Ordovician successions is illustrated in Figure 4(a) which shows that these carbonates experienced three episodes of significant uplift after burial. The first episode occurred in relation to the Middle Caledonian Orogeny during the Late Ordovician, the second one in association with the Early Hercynian Orogeny during the Late Devonian, and the third one in response to the Late Hercynian Orogeny during the Late Permian [23, 24].

Three major episodes of abnormal thermal events took place in the basin scale after the burial of Cambrian carbonate successions. The first episode occurred during the Early Ordovician but only localized in the central-western part of the basin [28]. The second one, also the most intense one, took place extensively in the entire basin during the Early Permian [26-30] and was characterized by basic basalt lavas and/or intrusive diabases, and intermediate acidic magmas in the central and northern parts of the basin, respectively [28]. The last one was active during the Cretaceous but was only restricted around the margin of the basin [28].

2.3. Fault/Fracture System. In the dip-trending seismic profile across the well TS1 in the North Uplift of Tarim Basin, several high-angle (nearly vertical) tensional (or transtensional) faults with small displacement (downthrowing) are 


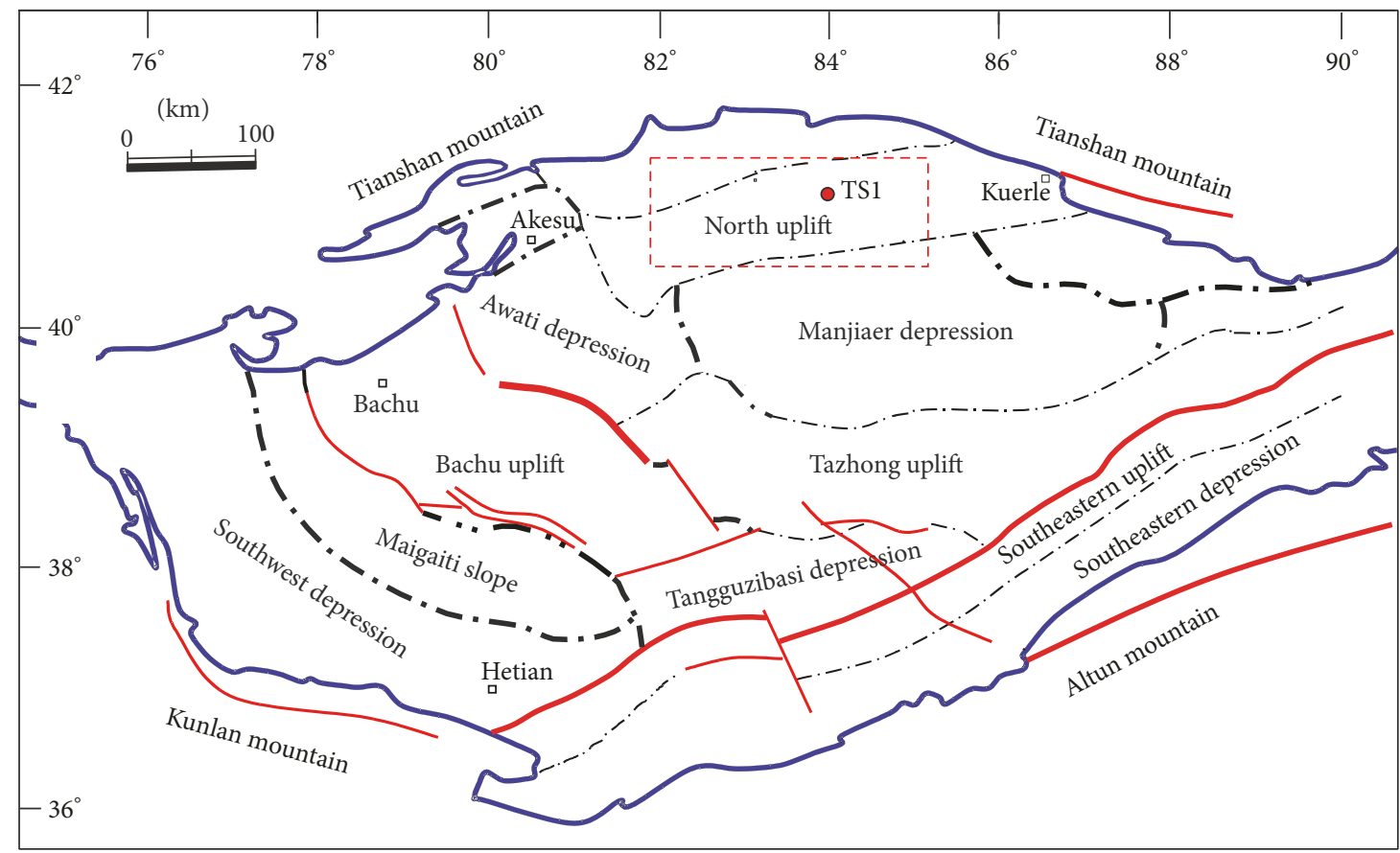

(a)

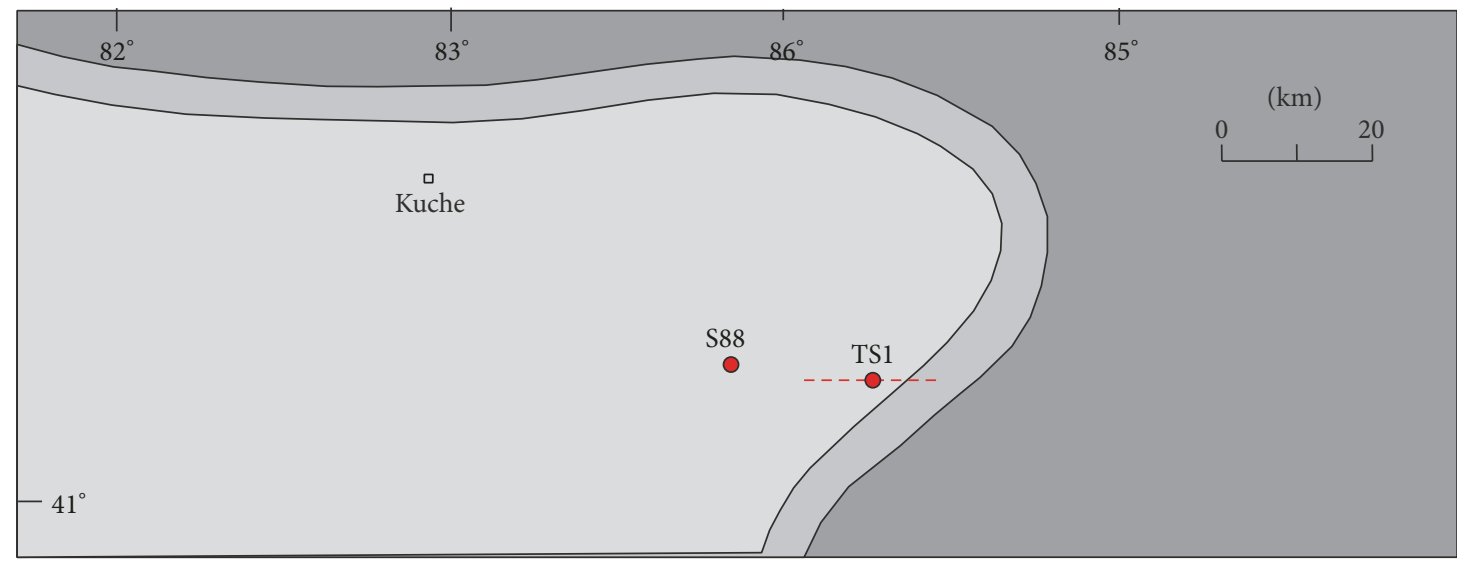

Drilling well

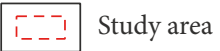

$\longrightarrow$ Fault system

Basin boundary
Shallow platform

Slope

Basin

(b)

FIGURE 1: (a) Map of the Tarim Basin showing the main tectonic units (modified from He et al., [23]). Dashed rectangle denotes the location of study area and TS1. (b) Palaeogeographic setting of the northern Tarim Basin (study area) during the Cambrian period (modified from [17-21]). Dashed line indicates the location of seismic profile shown in Figure 3.

identified, which cut the Precambrian-Cambrian boundary and partially extend upwards into the Ordovician (Figure 3). Extensive interpretations from the 3D seismic datasets demonstrate a dominance of conjugate (wrench) fault pattern composed mainly of NE- and NW-trending fault (or fracture) (X-shaped) series, respectively, with subordinate N-Strending tensional fault series in the Cambrian dolomites. In the northeastern part of this area, some E-W-trending 


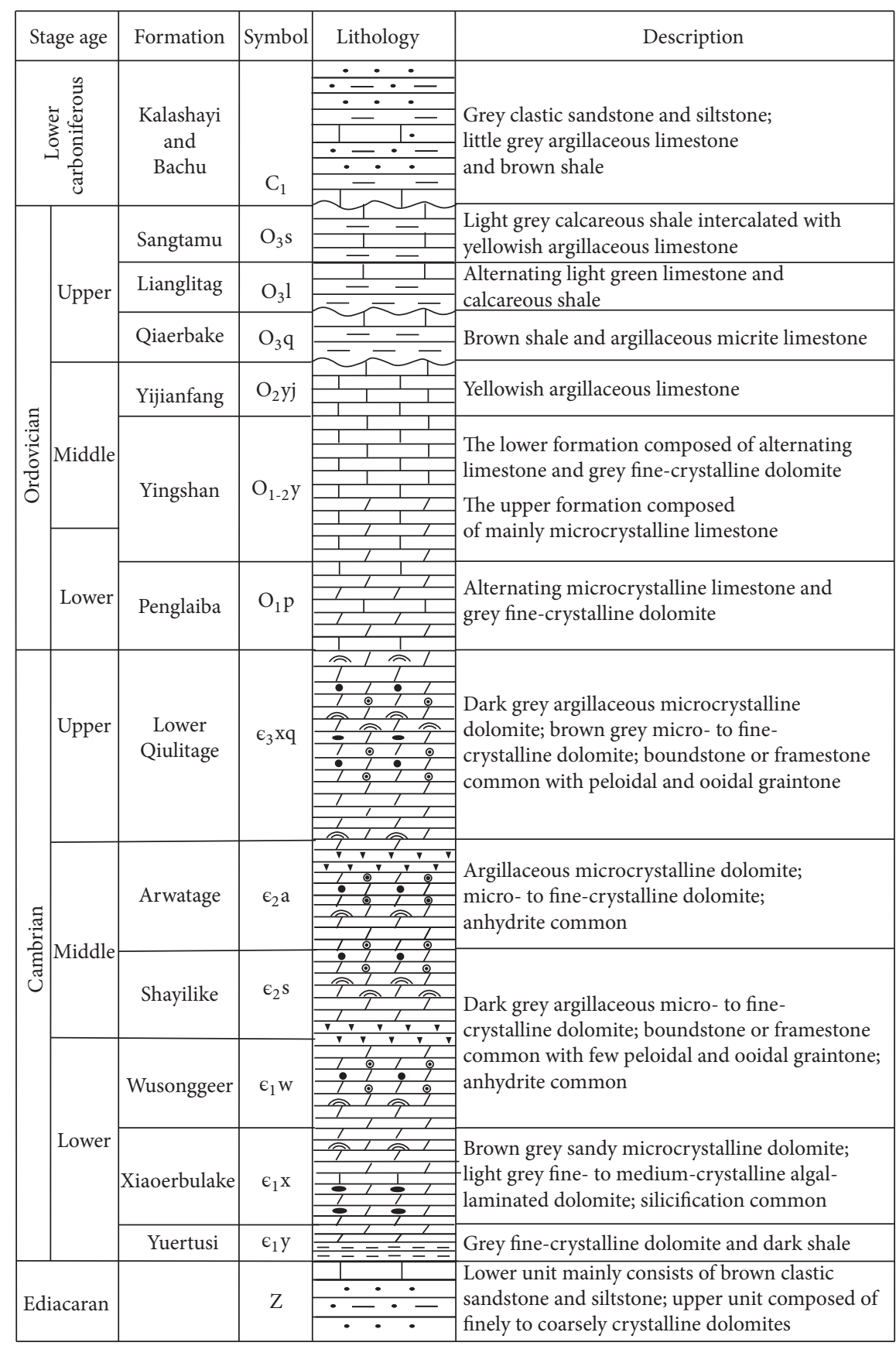
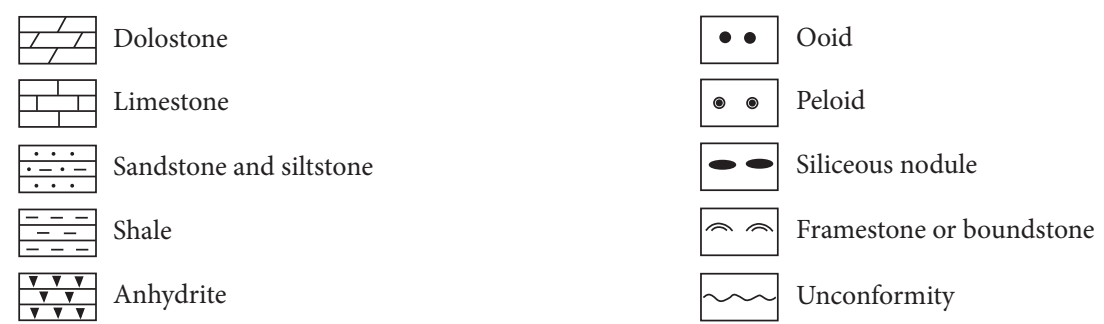

Figure 2: Generalized stratigraphic column from the Cambrian to Lower Carboniferous successions in the northern Tarim Basin, based on data from $[5,25]$. 


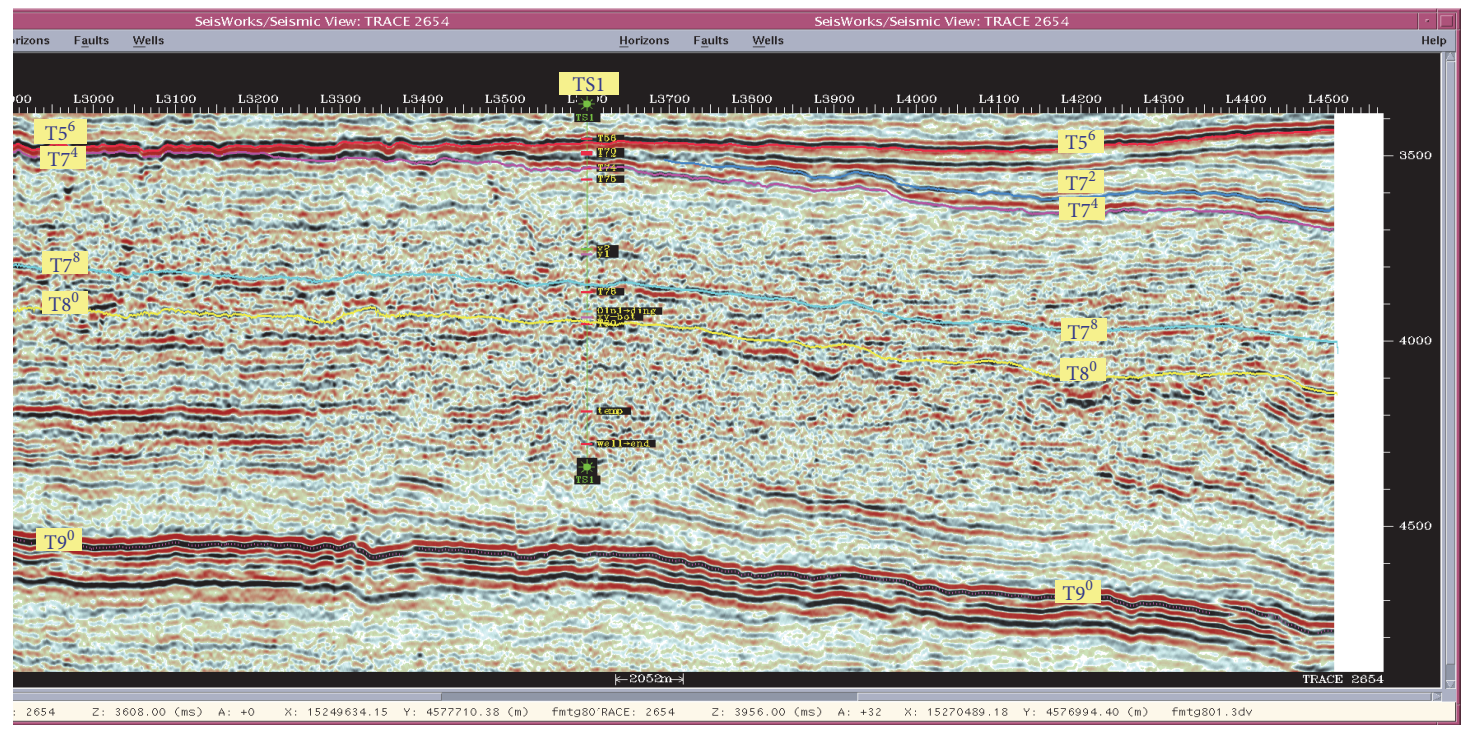

(a)

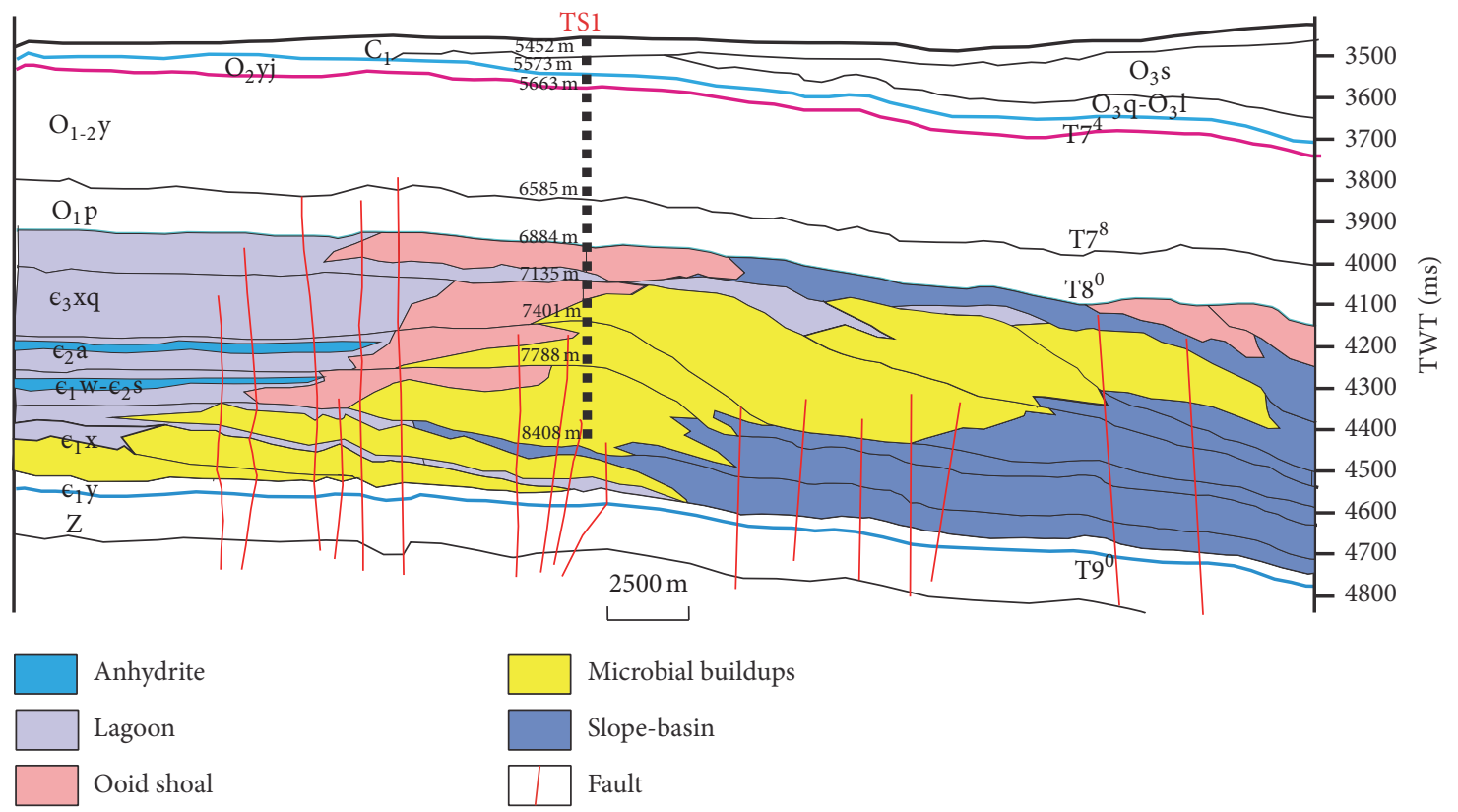

(b)

Figure 3: (a) E-W seismic profile across the TS1 (see Figure 1(b) for the location), showing the sequence architecture from the Cambrian to Lower Carboniferous. (b) Interpreted geological profile based on (a), displaying the distribution of lithologies, sequences, and faults. Refer to Figure 2 for the abbreviated symbols of stratigraphic formations. Z-Sinian (Neoproterozoic).

compressional fault series are also identified (Figure 5). As a whole, these fault (or fracture) series could have been induced by an overall compression from the north in view of their spatial distribution pattern. This compressional regime in the North Uplift may have been initially induced by the northward subduction of the South Tianshan oceanic crust bordering to the northern margin of Tarim block (present coordinate) beneath the Central Tianshan arc since the Late Ordovician [31-33] which could have caused the regional uplift of Tarim block marked by the widespread unconformity surface on the top of Upper Ordovician (Figure 2); this scenario, however, could have been greatly intensified from the Latest Carboniferous to Early Permian as a result of the final collision of the Tianshan arc accretionary complex and Tarim block and subsequent closure of the South Tianshan Ocean (or Palaeoasian Ocean) [31-33]. Under this circumstance, the previously formed conjugate X-shaped fault series could have been reactivated and additional N-S-trending tensional fault series and E-W-trending compressional fault series could have been further induced.

Small-scale fractures were also observed in cores, wellbore image logging of the Cambrian dolomites (Figures 6(a) and 6(b)). Based on kinematical characteristics and distributed location, fractures can be divided into two classes: 


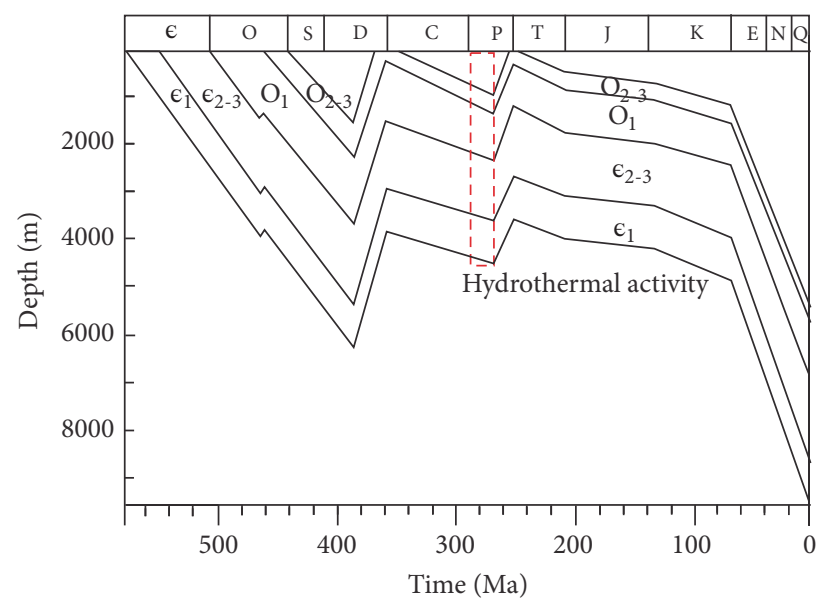

(a)

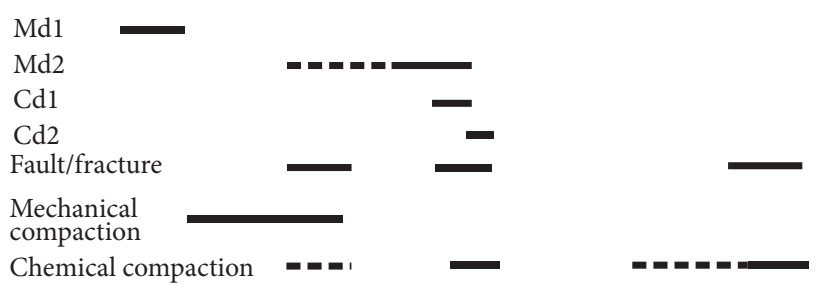

(b)

Figure 4: (a) Burial history curves of the Cambrian and Ordovician strata from well TS1 in the North Uplift (modified from Zhu et al., 2015). Dashed rectangle denotes the periods of Early Permian hydrothermal activity, based on data from [5, 26, 27]. (b) Paragenetic sequence of the main diagenetic events of Cambrian strata in the studied well. Dashed lines indicate uncertain timing or a long-term event.

shear fractures and tensional fractures (joints). The shear fractures are typically inclined (mostly less than $45^{\circ}$ ) to the horizontal strata and can be easily observed in cores and wellbore image (Figures 6(a) and 6(b)). The shear fracture was formed by compressive stress, which is generally required to overcoming the large compressive strength of carbonate rocks. Although it is difficult to determine the critical condition for shear failure, this scenario mostly occurs in or near fault zones [34]. Our observation also indicates that the shear fractures were more frequently encountered in the deep part of well TS1 near the fault zone (Figures 2, 6(a), and 6(b)).

The tensional fractures (joints) in sedimentary successions are commonly normal to the bed interfaces; however, they are rarely found in cores and wellbore image logging although some researchers [35] claimed the predominance of such fractures in the Cambrian strata. In relatively less deformed sedimentary rocks, the density of tensional fractures is typically controlled by stratification rather than faulting or folding [36]. The tensional fractures are generally more abundant than shear fractures in the country rocks. This is attributed to the fact that the tensile strength is much lower than the compressive strength, so it can be easily formed in shallow crustal conditions [34]. The distance of adjacent tensional fractures is generally larger than or equal to the thickness of complete stratigraphic (mechanic) unit (i.e., integrated stratified beds) known as fracture-saturation (Figure 6(c); [36]). In this case, the density of tensional fractures was much lower than that of shear fractures in fault zones which were more or less connected with stratigraphic (stratified) interface, serving as an effective network for fluid flow (Figure 6(c)).

2.4. Diagenesis and Dolomitization. Several hydrocarbon wells have been drilled to the depth over $8000 \mathrm{~m}$ in the northern uplift of Tarim Basin [5]. Of these, the borehole TS1 is the deepest one penetrated up to $8408 \mathrm{~m}$ deep with abundant dissolution pore spaces (vugs and fractures) preserved in the cores samples of Cambrian, providing an unique dataset for understanding how these pore spaces were generated by basinal or hydrothermal fluids during burial and/or structural diagenetic processes. The diagenetic processes of dolomite rocks in the North Uplift have been studied by several researchers $[5,25,37,38]$. The main diagenetic events including dolomitization, mechanical and chemical compaction, fracturing, and structural-related hydrothermal dissolution and pore plugging (cementation) (Figure 4(b)).

Based on petrographic observations, four types of dolomite are recognized in the matrix and cement. Of these, two types are matrix dolomites (Figures $7(\mathrm{a})-7(\mathrm{e})$ ): (1) fabricretentive (mimetic) dolomite (Md1) and (2) medium to coarse crystalline fabric-obliterated nonplanar-a (anhedral) dolomite $(\mathrm{Md} 2)$, and two types are cement dolomites: (3) medium to coarsely crystalline planar-s (subhedral) dolomite (Cd1) and (4) coarsely crystalline nonplanar-a saddle dolomite (Cd2) (Figure 7(f)). 


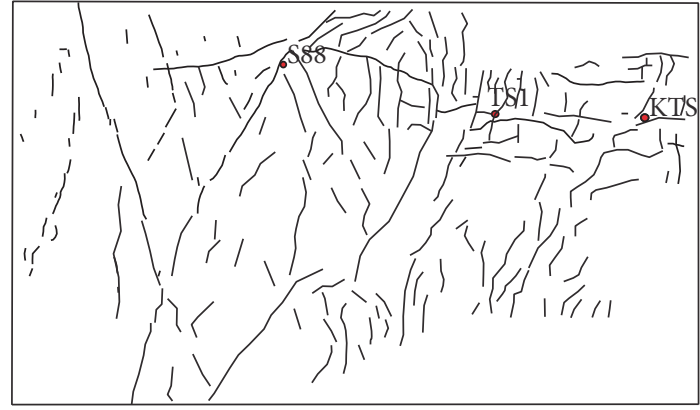

(a)

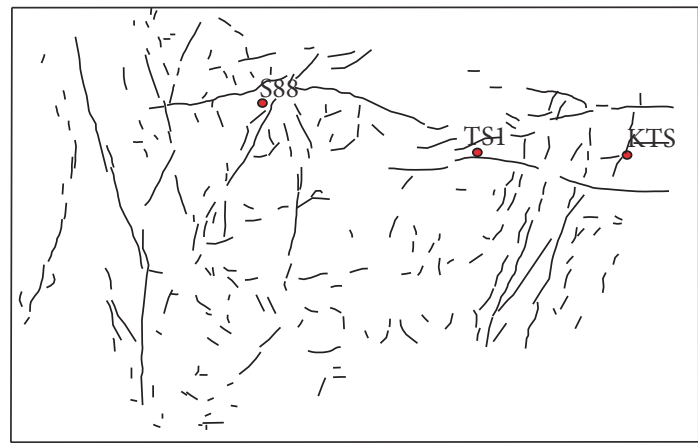

(b)

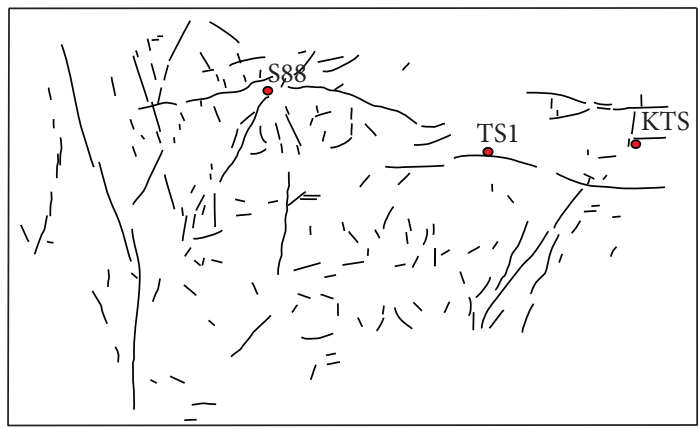

(c)

FIGURE 5: Spatial patterns of fault/fracture systems on some important stratal levels traced by seismic reflection surfaces in northern Tarim. (a) $\mathrm{T}^{0}$ (lower surface of Cambrian formation), (b) $\mathrm{T} 8^{0}$ (upper surface of Cambrian formation), and (c) $\mathrm{T}^{8}$ (upper surface of Lower Ordovician Penglaiba Formation) as indicated in Figure 3. Note the location of borehole TS1.

The Md1 dolomites are the most abundant matrix dolomites with a wide spectrum of retentive fabrics (or texture) including mudstone to grainstone and diversified microbialites (microbial laminite, stromatolite, and thrombolite) and other subordinate fabrics (or textures) such as dissolution fabrics so that crystals vary widely in size from dolomicrites within primary grains and/or microbial framework, to medium equant crystals in intercrystalline pores of packstone to grainstone or fenestral and framework pores of microbialites (Figures $7(\mathrm{a})-7(\mathrm{~d})$ ). Locally, extracellular polymeric substances (EPS) are found in microbially originated fabrics [39]. This type of dolomite generally demonstrates similar isotope $(\mathrm{O}-\mathrm{C}-\mathrm{Sr})$ values to those of coeval seawater $[5,25,38]$.
The primary depositional environments of these diverse Md1 dolomites varied from microbial reefs (or buildups) to ooidal shoal which could have aggraded to the tidal flat (Figure 1(b)). The preservation of mimetic fabrics (or textures) of primary sediments suggests they could have been formed either by microbial mediation, particularly for those microbial dolomites (Figures 7(a) and 7(b)) during deposition [39], or by penecontemporaneous dolomitization driven by reflux of more saline seawater in the protected lagoon through the ooidal shoal-microbial reefs on the platform margin $[25,38]$ (Figure 7(c)).

The Md2 dolomites, the second important matrix dolomites, are fabric-obliterated with rare ghosts of primary fabrics/textures. These dolomites, generally 100 to $200 \mu \mathrm{m}$ in size, are exclusively composed of nonplanar-a dolomite mosaics with few intercrystalline pore spaces (Figures $7(\mathrm{~d})$ and $7(\mathrm{e}))$. This type of dolomite generally demonstrates similar $\delta^{13} \mathrm{O}$ and ${ }^{87} \mathrm{Sr} /{ }^{86} \mathrm{Sr}$ values to those of Mdl dolomite although more negative $\delta^{13} \mathrm{O}$ values and radiogenic ${ }^{87} \mathrm{Sr} /{ }^{86} \mathrm{Sr}$ ratios are present as well $[5,25]$. All these data suggest a similar fluid in which $\mathrm{Md} 2$ dolomites had precipitated, at elevated temperature $[5,25,38]$.

The Cd1 dolomites, 50 to $500 \mu \mathrm{m}$ in size, are characterized by planar-s to planar-e crystals which commonly occur as the initial cements lining the vuggy and fracture pore spaces (Figure 7(f)). Their close association with fracture implies that fracturing could have provided necessary conduits for fluid migration from depth, promoting initial dissolution and subsequent precipitation of $\mathrm{Cd} 1$ dolomite along the walls of vugs and fractures.

The Cd 2 dolomites, $200 \mu \mathrm{m}$ to $2 \mathrm{~mm}$ in size, are composed of coarse nonplanar-a saddle dolomites with halfmoon termination (Figure 7(f)). These saddle dolomites are mostly grown directly over the walls and rarely sit over the Cdl crystals in vugs and fractures so that their precipitation was also closely associated with fracturing as well. The Cd2 dolomites generally have similar $\mathrm{C}$ but more negative $\mathrm{O}$ isotope values to those of matrix dolomites [38], suggesting that the $\mathrm{Cd} 2$ dolomites likely precipitated from highertemperature dolomitizing fluids mostly sourced from the ambient aquifer in the host dolomite rocks [16].

2.5. Hydrothermal Activity and Dolomite Dissolution. Numerous studies have demonstrated a strong Early Permian large igneous province (LIP) (mantle plume?) activity in the Tarim Basin [40, 41]; this could have exerted a substantial influence on the carbonate rocks including the Cambrian dolomites as they were penetrated by the intrusive diabases and volcanic eruptive edifice through thermal baking, enhanced thermal anomaly (or gradient), and/or hydrothermal fluid inputs $[5,25,27,38]$. On the other hand, the high-angle conjugate (wrench) fault system that penetrated the Cambrian dolomites may have been developed and/or reactivated from the latest Carboniferous to the Early Permian as a result of collision of Tianshan arc accretionary to the north with Tarim block $[31,33]$. Under this overall compressional (or transpressional) tectonic regime in the Tarim block, particularly in the northern part where the deep well TS is located, these faults and associated fractures could have 


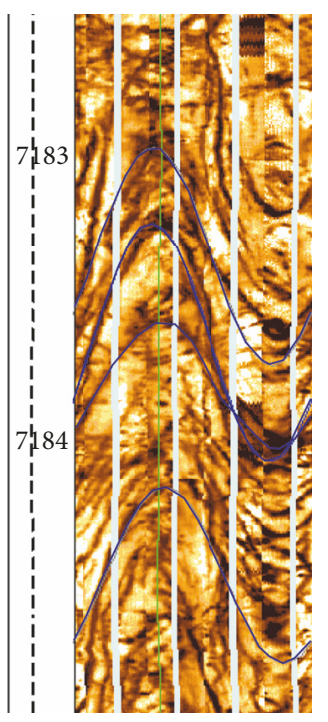

(a)

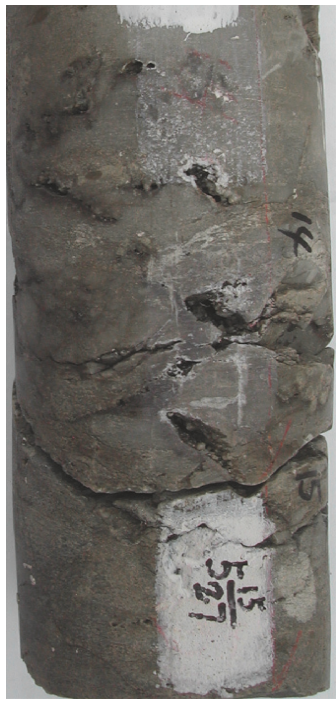

(b)

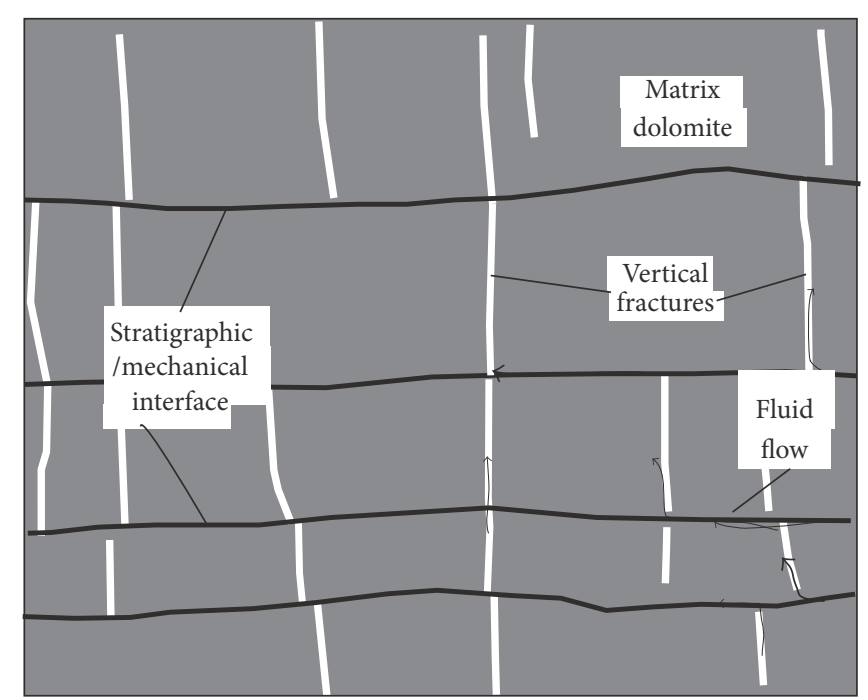

(c)

FIGURE 6: (a) Wellbore image logging shows the development of shear fractures on the wall, well TS1. (b) Borehole cores show the development of low-angle shear fractures at depths of $8407 \mathrm{~m}$, well TS1. Note the vugs developed by dissolving enlargement along the fractures. (c) Stratigraphic controls tensional fracture patterns. Fractures develop within mechanical units and normal to the stratigraphic interfaces. The tensional fractures can serve as an effective network for fluid flow.

formed a complicated conduit network through which the hydrothermal fluids from depth could have readily migrated upwards and caused dissolution upon the host dolomites. The preferential occurrence of large less-filled vugs (up to several centimeters in size and $10 \%$ in porosity) along fractures in the Cambrian dolomites, particularly in the lower part of this drilled well ( $\sim 8408 \mathrm{~m}$ deep) close to the fault (Figure 8 ), generally supports intensive dissolution upon the host dolomites and fracture enlargement likely by the fracture/fault-channeled, upflowing hydrothermal fluids from a greater depth; otherwise, few porosities could have remained at such a great depth [3]. The subsequent precipitation of more or less saddle dolomite cements further attests to a hydrothermal fluid in which they were precipitated as the $\mathrm{Mg}$ ions increased and reached the saturation relative to dolomite [5]. This scenario also agrees with upward-increasing distribution of pore-filling saddle dolomite cements (Figure 8). Moreover, the higher homogenization temperatures $\left(122-153^{\circ} \mathrm{C}\right)$ of $\mathrm{Cd} 2$ dolomite in the Cambrian succession than the normal burial temperatures $\left(68-105^{\circ} \mathrm{C}\right)$ during the Early Permian $[5,25]$ confirm the attribute of hydrothermal fluids.

\section{Reactive Transport Modeling}

3.1. Methods. In this study, the numerical program TOUGHREACT V2 [9] was used to investigate the hydrothermal dissolution and porosity generation in the deepest borehole TS1 in the Tarim Basin (Figure 1). This program is a nonisothermal RTM coupled code capable of simulating multiphase fluid flow, heat, and chemically reactive solution transport and has been used previously to simulate carbonate diagenesis, notably dolomitization $[7,11]$.

The numerical model is based on the geological architecture along the E-W trending transection across the well
TS1 in the northern Tarim Basin along which stratal and structural patterns were unveiled by $3 \mathrm{D}$ seismic reflectors and more specifically constrained by the borehole data of TS1 on aspects of horizon calibration, petrography, and petrophysics. During the Early Permian, subsurface strata, in ascending order, include the Neoproterozoic, Cambrian, Ordovician, and Carboniferous successions (Figures 2 and 3). The model domain covers an area with a width of $35 \mathrm{~km}$ from west to east and a height of 3700 to $4000 \mathrm{~m}$ eastward; it is further divided into cells $350 \mathrm{~m}$ wide and decreased to $100 \mathrm{~m}$ close to the well TS1 area to give a higher-resolution characterization for the permeability heterogeneity around the fault zone. The whole grid system comprises 7320 active cells (Figure 9). The unstructured grid system is created by PetraSim which is an interactive graphical interface preprocessor for TOUGHREACT. In the model domain, it is assumed that all boundaries (including right, left, bottom, and top boundaries) are fluidpressure boundaries, allowing recharge or discharge of fluids driven by hydrostatic pressure. The top boundary represents an earth surface condition with a temperature of $25^{\circ} \mathrm{C}$ and one atmospheric pressure. Initial burial temperature for all boundaries and model domain is determined specifically with a thermal gradient of $3.5^{\circ} \mathrm{C} / 100 \mathrm{~m}$ based on the regional geothermal history [26]. The fluid pressure for the model domain and boundaries is presumably dominated by hydrostatic pressure with a gradient of $1 \mathrm{MP} / 100 \mathrm{~m}$.

3.2. Petrophysical Model. The permeability of Cambrian dolomite rocks could have been influenced by the primary deposition, multiple diagenesis, and fracturing- or faulting-related fluid activity. Many permeability data show that most of the Cambrian dolomite samples yield the permeability values lower than the detection limits, but a few samples still follow the porosity-permeability (P-P) relationship 


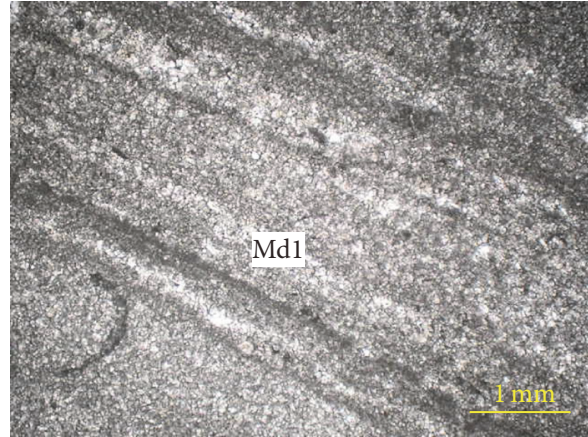

(a)

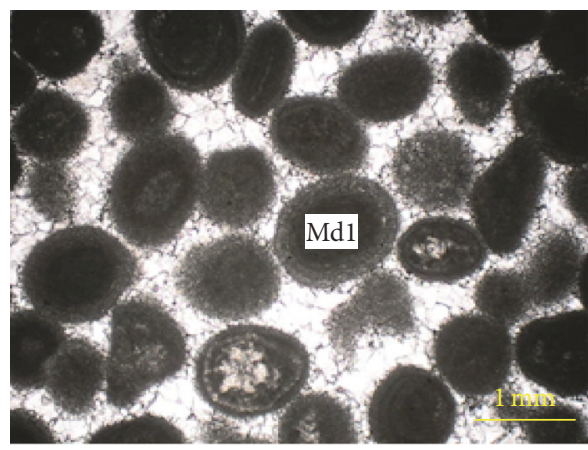

(c)

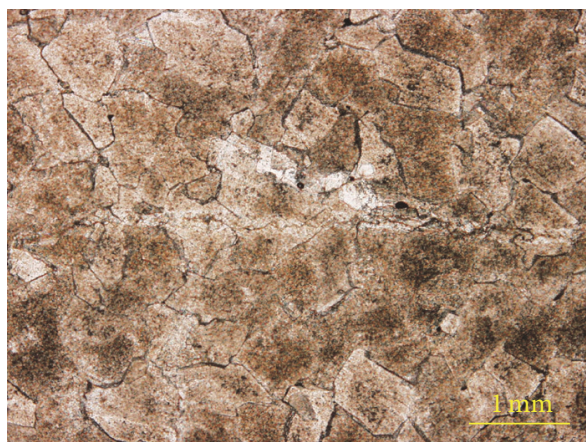

(e)

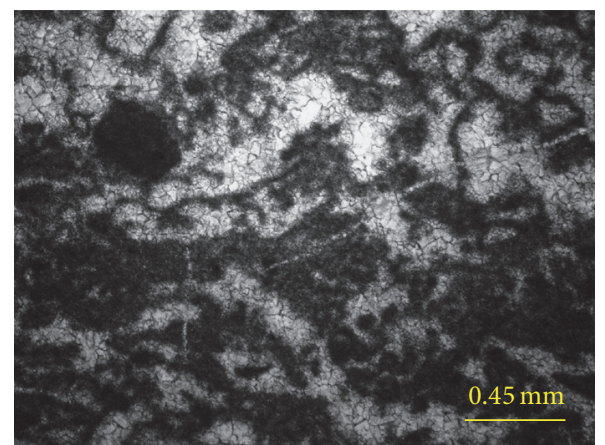

(b)

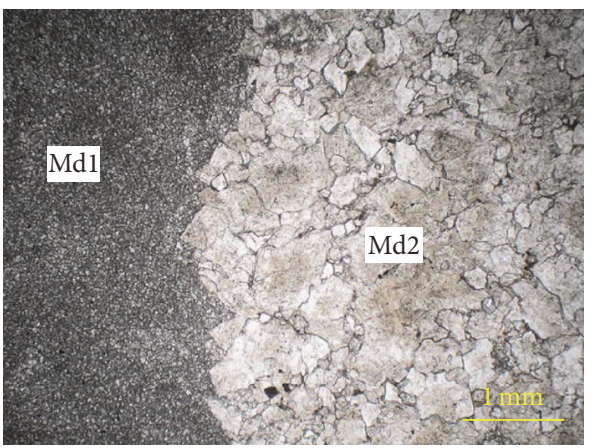

(d)

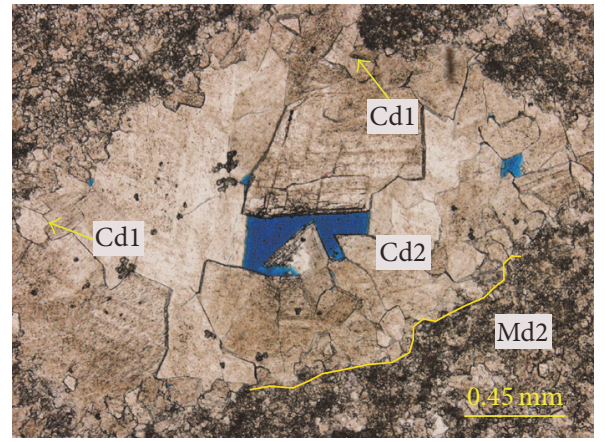

(f)

FIGURE 7: Photomicrographs showing different types of dolomites in Cambrian strata in well TS1. (a) Dark-brown to black, organic-rich laminated microbial dolomite (Md1), $7690 \mathrm{~m}$. (b) Photomicrographs of microbial boundstones in platform margin reefs. Note the wellpreserved original microbial fabric (Md2), $7875.7 \mathrm{~m}$. (c) Photomicrographs of fabric-retentive dolomite (ooidal grainstone) (Md2) cemented with thin fibrous (or bladed) and equant dolomite crystals, $7710 \mathrm{~m}$. (d) Very finely crystalline, fabric-retentive micrite (dolomicrite) (Md1) with medium-crystalline fabric-obliterative dolomite (Md2), $8030 \mathrm{~m}$. (e) Medium to coarse crystalline fabric-obliterative dolomite (Md2), $7155 \mathrm{~m}$. (f) Photomicrograph showing cement dolomites in the vug developed in the matrix dolomite: the initial medium-crystalline planar-s (subhedral) dolomites (Cd1) and subsequent coarse crystalline saddle dolomites (Cd2) which are characterized by curved crystal faces and undulose extinction. $7875 \mathrm{~m}$. Note the relict pore space in vug center (blue resin).

(Figure 10). This implies that the P-P relationship proposed by Lucia [42] can still be used to estimate the permeability of the Cambrian dolomites during the Permian Period, but the impact of diagenesis should also be considered. In the studied borehole section of TS1 and adjacent area, there are five major primary lithological types in the Cambrian succession: peloidal-ooidal grainstone (Gs), packstone (Ps), wackestone (Ws), mudstone (Ms), and microbial boundstone (Bs) (Figure 9).
Based mainly on the permeability data, the dolomite rocks are tentatively classified into three classes: classes 1 to 3 with decreasing permeability (Figure 10). In view of the high uncertainty for the P-P relationship due to strong diagenetic alterations on the dolomite rocks, three scenarios (I to III) (Table 1) are further presumed to test which case is more close to the reality during the course of intense dissolution on the dolomite host. As documented above, the primary dolograinstones were strongly cemented (Figure $7(\mathrm{c})$ ) and/or 


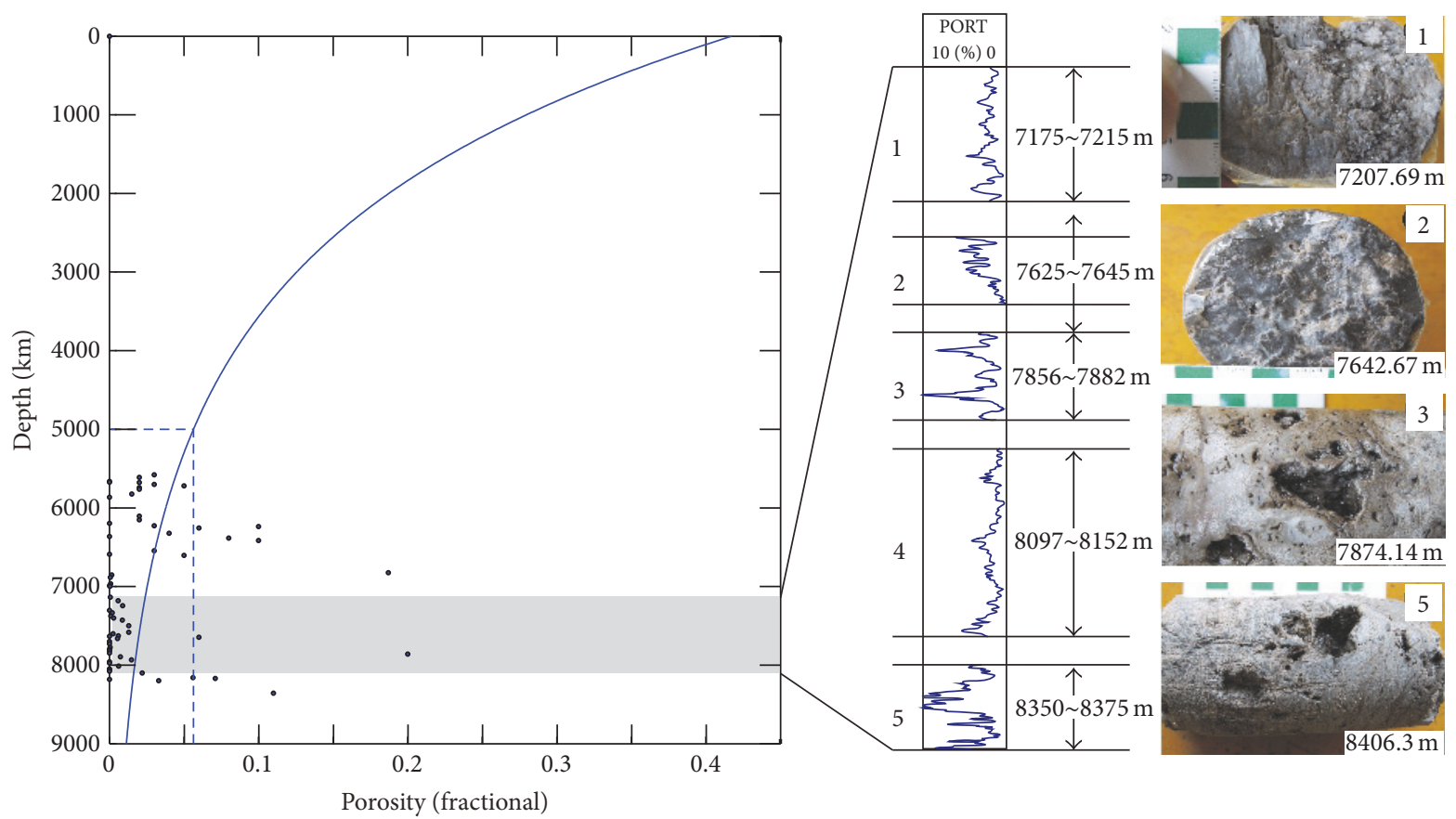

(a)

(b)

FIgURE 8: (a) Plot of porosity derived from well logging interpretation against depth in well TS1. The solid line shows the porosity-depth relationship of carbonates according to Schmoker and Halley (1982). The dashed rectangle shows the porosity ranges of carbonates buried below depth of $5000 \mathrm{~m}$. (b) Porosity variations interpreted from well logging in intervals 1-5 with core photos. Note prevalence of dissolved, less-cemented open vugs present in the deeper part of the well.

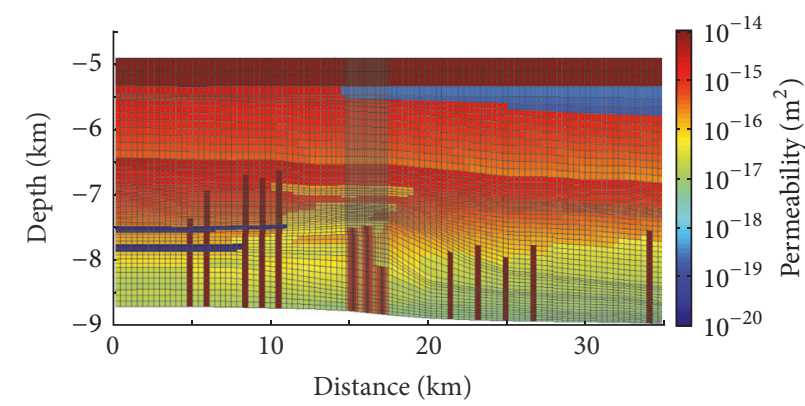

(a)

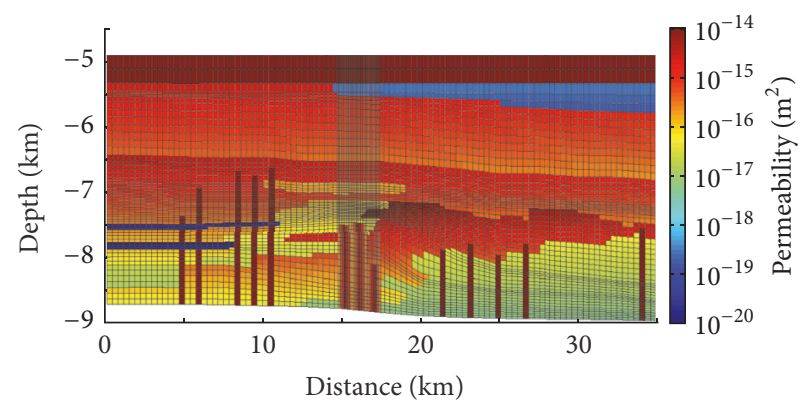

(b)

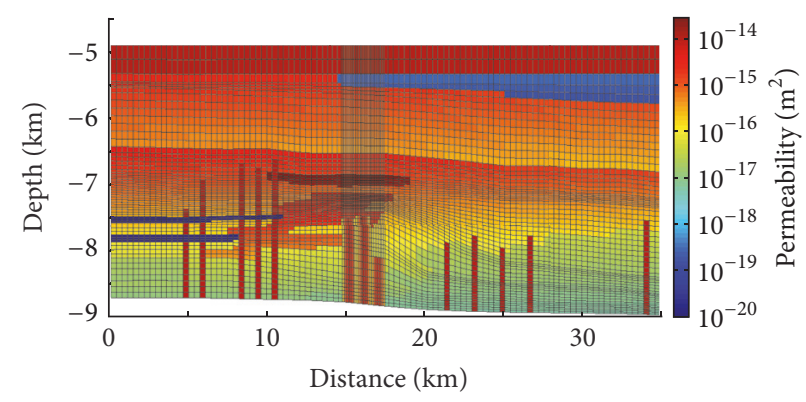

(c)

FIGURE 9: Initial values of horizontal permeability used in simulations for Scenario I (a), Scenario II (b), and Scenario III (c). Note that the permeability was assigned to different stratigraphic and lithologic units based on Figure 3. The lithologic units which are not displayed in Figure 3 are assigned based on the stratigraphic description in Figure 2. 


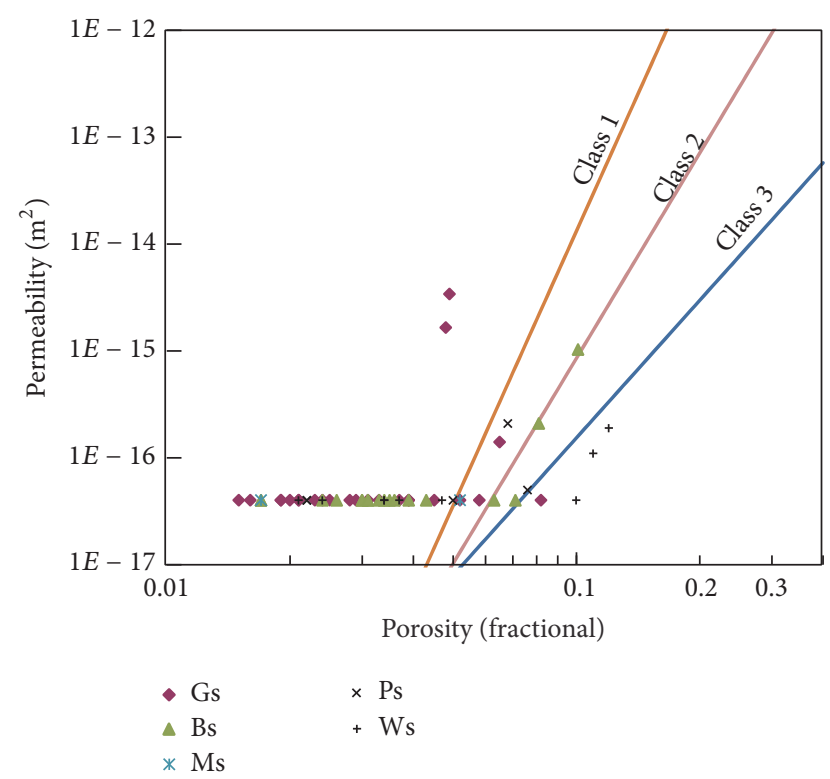

Figure 10: Crossplots of porosity and permeability for different types of dolomite rocks. Note the three lines which show the three classes of porosity-permeability relationship according to Lucia (1995). The permeability of the detection limit is $4 \times 10^{-17} \mathrm{~m}^{2}$.

TABLE 1: Assignment of permeability class and scenario for dolomite rocks used in simulation.

\begin{tabular}{lccc}
\hline & Scenario I & Scenario II & Scenario III \\
\hline Grainstone & Class 3 & Class 3 & Class 1 \\
Microbial reefs & Class 2 & Class 1 & Class 2 \\
Packstone & Class 2 & Class 2 & Class 2 \\
Wackestone/mudstone & Class 3 & Class 3 & Class 3 \\
\hline
\end{tabular}

recrystallized (Figure 7(e)) mostly with extremely low porosity and permeability (Figure 10) so that this type of dolomite is initially assigned to class 3 . For comparison, it is also assigned to class 1 in another scenario (III) in view of the relatively high permeability in some of this type of dolomite which may have been not substantially plugged before or during the significant dissolution. Although the microbial reefs or buildups (boundstones) on the platform margin may have relatively high volumes of primary fenestral or framework porosity, their permeability, which is highly dependent on whether the pores are connected or not, is not necessarily high accordingly. Therefore, this type of dolomite is assigned to class 2 (intermediate) in two scenarios (I and III) and to class 1 in one scenario (II) for a comparison (or sensitivity test). Dolopackstone, dolowackestone, and dolomudstone are generally fabric-retentive, with rare cements and weak diagenetic modification. Of these, dolopackstones roughly yield an intermediate permeability (Figure 10), so that it is tentatively assigned to class 2 in all scenarios. In contrast, dolowackestone and dolomudstone generally yield the lowest permeability, so that they are collectively set to class 3 in all scenarios.

Other rocks except dolomites are set with a consistent permeability without sensitivity test for the P-P relationship.
As documented above, in the Cambrian platform interior succession, there are widespread evaporites (mostly anhydrites) occurring in the Awatage Formation (Figure 3) which are generally thought as the impermeable aquitard; its permeability is thus set to $1 \times 10^{-20} \mathrm{~m}^{2}$ [43], almost impermeable to fluids. Above the Cambrian, the Lower Ordovician Penglaiba Formation is dominated by the shoal dolomites (grainstone) in the lower part which pass upward into shelfal interbedded dolomites and limestones, so it is tentatively set to class 3 in the lower part and class 2 in the upper part. The overlying Yinghshan and Yijianfang formations of the Lower-Middle Ordovician mainly comprise the wackestone and lime mudstone with relatively low porosity and permeability; they are thus assigned to class 3. Further upwards, the Upper Ordovician comes which mainly comprises the argillaceous limestones (wackestones and mudstones) intercalated with black shales deposited on the offshoal shelf; this argillaceous-rich succession is thus regarded approximately as corresponding to the shale. The permeability of shales is estimated based on the P-P relationship proposed by Harrison and Summa [44]. The Upper Ordovician is toplapped by the major unconformity surface on which it is overlain by the Carboniferous strata which are mainly composed of sandstones (Figure 2). These sediments were laid near the Earth surface during the Early Permian. The permeability near Earth surface may have significantly increased so that it cannot be reasonably described by the P-P relationship [45]. In our model, the permeability of Carboniferous sandstones is set to $1 \times 10^{-14} \mathrm{~m}^{2}$, consistent with the previously reported permeability values near the Earth surface [45]. Petrophysical variations along the profile across the well TS1 are illustrated in Figure 9.

The development of tensional or transtensional fracture networks in wall-rock (Figure 6(c)) commonly increases the vertical permeability substantially. To study the influence of tensional/transtensional fractures, the permeability anisotropy $\left(k_{\text {horizontal }}: k_{\text {vertical }}\right)$ ranging from 1 to 100 was tested in the simulations.

The permeability in fault zones varies significantly in space and time [46]. Ingebritsen and Manning [47] observed that the drastic increase in crust permeability (100 to 1000 times) could occur through the tectonic activity (e.g., seismic rupturing). In our baseline modeling, the fault permeability is set to $1 \times 10^{-14} \mathrm{~m}^{2}$ which is approximately 100 times higher than that of the host rock. In addition, sensitivity tests for permeability in fault zone were conducted by one order of increase or decrease in magnitude.

The initial fluid composition was constrained by fluid inclusion data derived from hydrothermal-originated minerals such as saddle dolomite, fluorite, barite, and quartz present in the Paleozoic carbonates [48], which is assumed to be equilibrium with dolomite at the temperature of the bottom influx boundary (Table 2). In contrast to the precipitation of dolomite, the dissolution of dolomite is generally considered as an equilibrium reaction process $[9,49]$. Although kinetic reaction process can also be modeled by the TOUGHREACT [9], thermodynamic reaction modeling can reach convergence through iteration more rapidly (or efficiently), leading to more precise results [9] due to the small variance of saturation index in the simulation. 


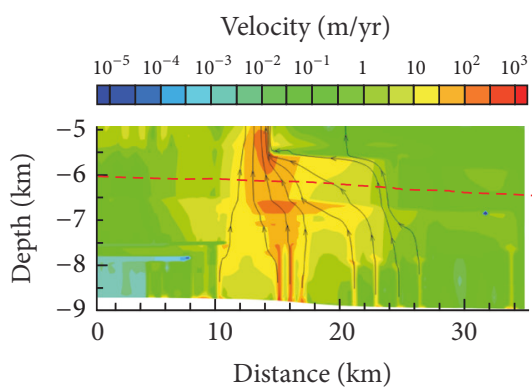

(a)

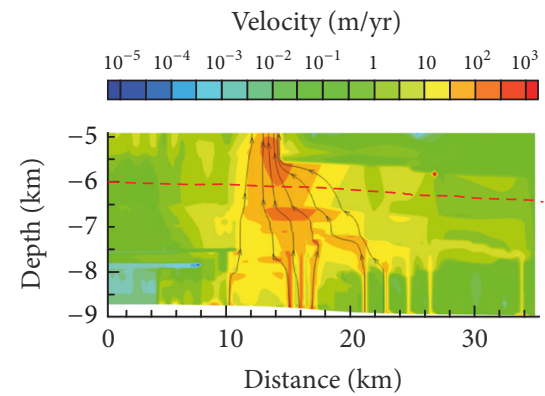

(d)

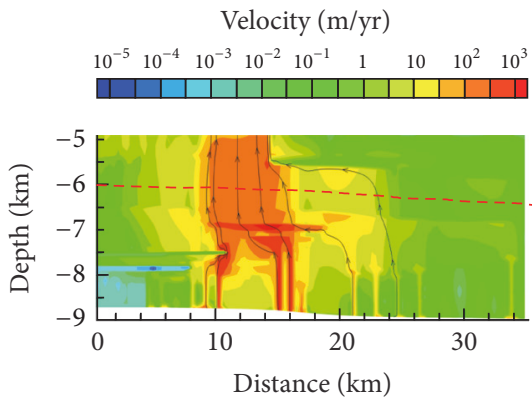

(g)

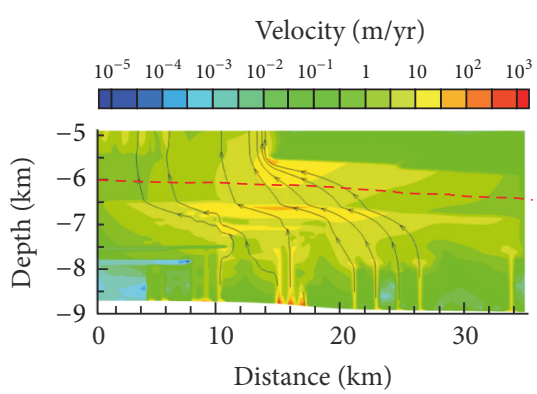

(b)

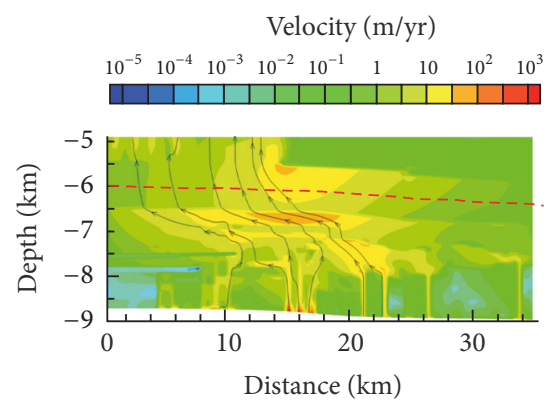

(e)

Velocity $(\mathrm{m} / \mathrm{yr})$
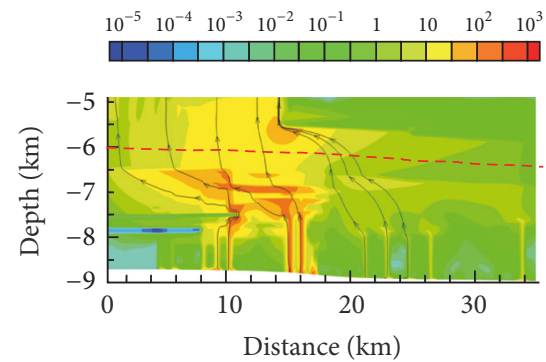

(h)

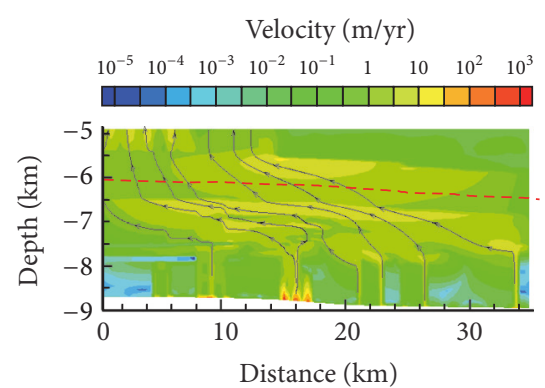

(c)

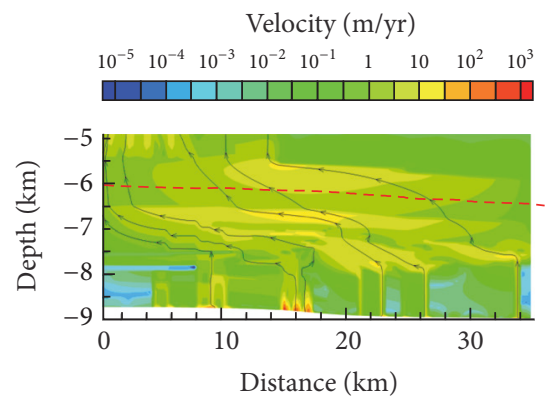

(f)

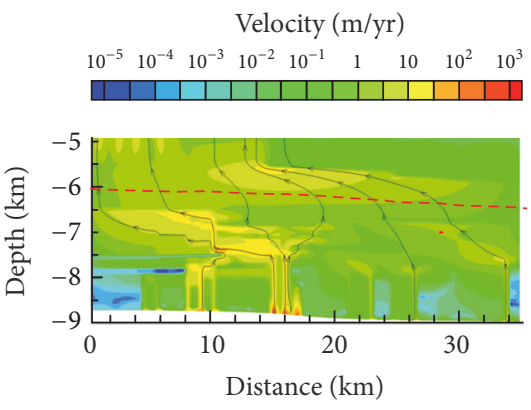

(i)

FiguRE 11: The fluid velocity for Scenario I: (a) $k_{\mathrm{h}}: k_{\mathrm{v}}=1$, (b) $k_{\mathrm{h}}: k_{\mathrm{v}}=10$, and (c) $k_{\mathrm{h}}: k_{\mathrm{v}}=100$, Scenario II: (d) $k_{\mathrm{h}}: k_{\mathrm{v}}=1$, (e) $k_{\mathrm{h}}: k_{\mathrm{v}}=10$, and (f) $k_{\mathrm{h}}: k_{\mathrm{v}}=100$, and Scenario III: (g) $k_{\mathrm{h}}: k_{\mathrm{v}}=1$, (h) $k_{\mathrm{h}}: k_{\mathrm{v}}=10$, and (i) $k_{\mathrm{h}}: k_{\mathrm{v}}=100$. The arrow lines indicate the general pathways of fluids. Note the model domains below the dashed lines which were arranged for plotting dissolved porosity in Figure 15.

TABLE 2: Initial fluid composition.

\begin{tabular}{lc}
\hline Component & Total aqueous concentration $(\mathrm{mol} / \mathrm{kg})$ \\
\hline $\mathrm{Na}^{+}$ & 1.13 \\
$\mathrm{~K}^{+}$ & 0.05773 \\
$\mathrm{Ca}^{+2}$ & 0.206 \\
$\mathrm{Mg}^{+2}$ & 0.0438 \\
$\mathrm{Cl}^{-}$ & 1.686 \\
$\mathrm{HCO}_{3}{ }^{-}$ & 0.57179 \\
$\mathrm{SO}_{4}{ }^{-2}$ & 0.0193 \\
$\mathrm{pH}^{-}$ & 7 \\
\hline
\end{tabular}

\section{Results}

The reactive transport model is mainly used to analyze the fluid flow, accompanying formation temperature, and spatial distribution of dissolved porosity as well as sensitivity of fault zone permeability. The spatial pattern of fluid flow and temperature will determine the final distribution of dissolved porosity.

4.1. Spatial Pattern of Fluid Flow. Modeling results show that the fluid was dominantly driven to flow in the dolomites of platform margin and was significantly suppressed in dolomites of platform interior and slope due to the presence of Middle Cambrian low permeable evaporative deposits and Upper Ordovician shaly limestones and shales, respectively (Figure 11).

In platform margin dolomites, upward-flowing fluids driven by the difference of formation pressure predominated. In the low part of model domain, upflowing fluids were focused in the fault zones which would flow laterally into the permeable country dolomites near the top of faults.

Permeability anisotropy has an important control on fluid and temperature patterns. For the low permeability anisotropy $\left(k_{\mathrm{h}}: k_{\mathrm{v}}=1\right)$, the fluids mainly flow vertically 


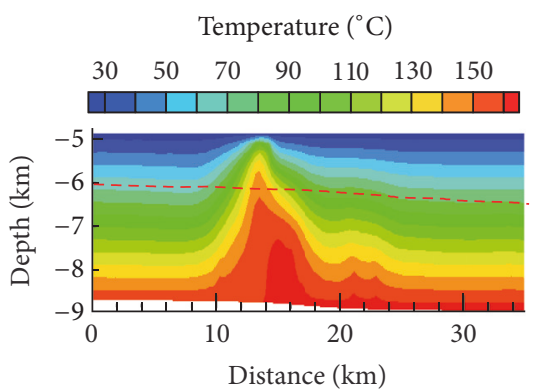

(a)

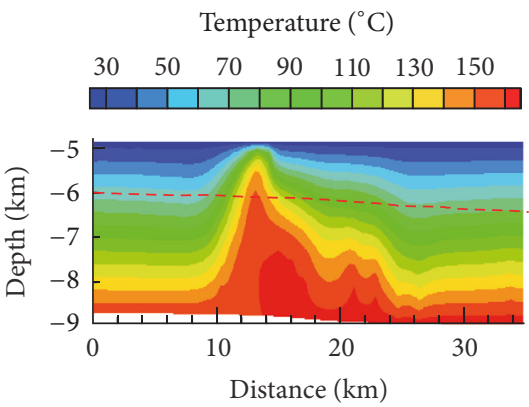

(d)

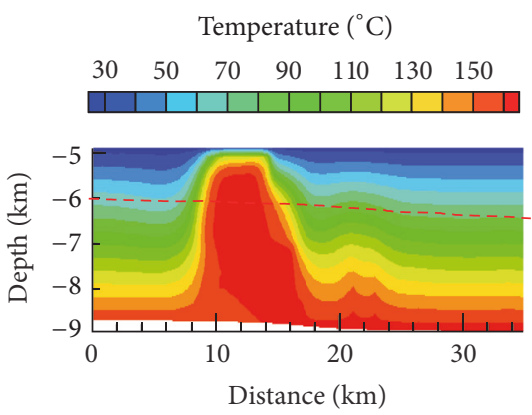

(g)

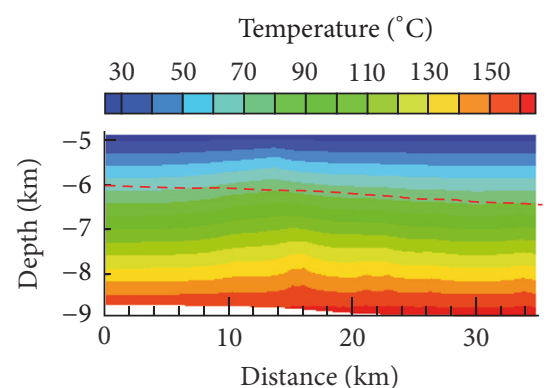

(b)

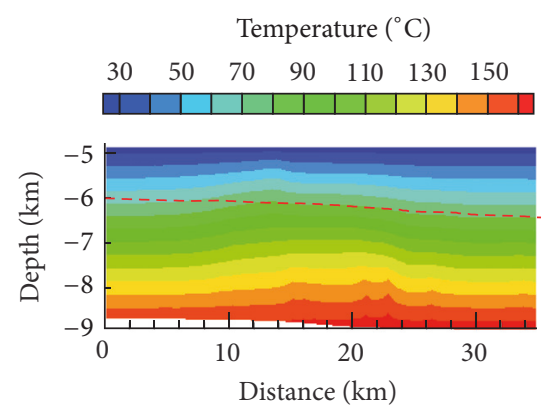

(e)

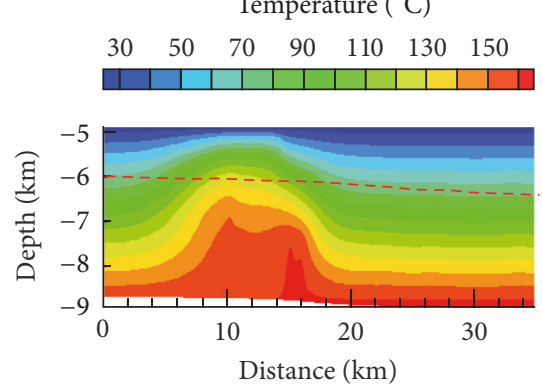

(h)

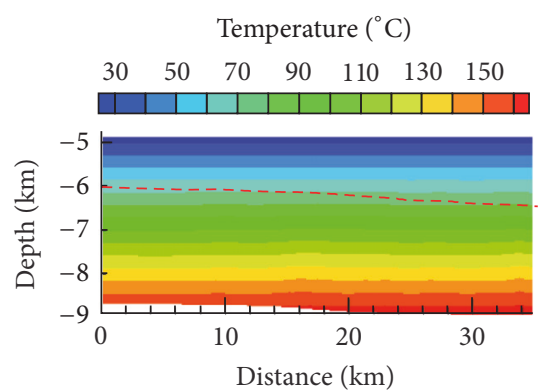

(c)

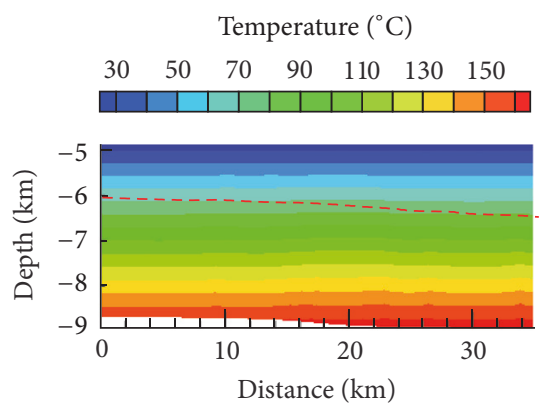

(f)

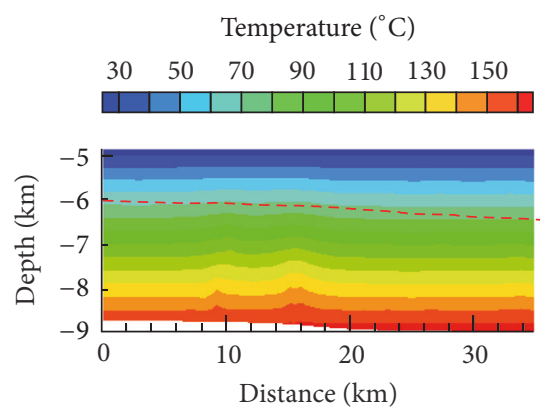

(i)

FIgURE 12: The temperature patterns of Scenario I: (a) $k_{\mathrm{h}}: k_{\mathrm{v}}=1$, (b) $k_{\mathrm{h}}: k_{\mathrm{v}}=10$, and (c) $k_{\mathrm{h}}: k_{\mathrm{v}}=100$; Scenario II: (d) $k_{\mathrm{h}}: k_{\mathrm{v}}=1$, (e) $k_{\mathrm{h}}: k_{\mathrm{v}}=10$, and (f) $k_{\mathrm{h}}: k_{\mathrm{v}}=100$; and Scenario III: (g) $k_{\mathrm{h}}: k_{\mathrm{v}}=1$, (h) $k_{\mathrm{h}}: k_{\mathrm{v}}=10$, and (i) $k_{\mathrm{h}}: k_{\mathrm{v}}=100$. Note the model domains below the dashed lines which were arranged for plotting dissolved porosity in Figure 15.

(Figures 11(a), 11(d), and 11(g)). As permeability anisotropy increases $\left(k_{\mathrm{h}}: k_{\mathrm{v}}=10\right)$, some of fluids tend to flow laterally, and they would almost completely flow laterally as the anisotropy increases further $\left(k_{\mathrm{h}}: k_{\mathrm{v}}=100\right)$. Furthermore, permeability anisotropy, particularly the vertical permeability, also controls the fluid velocity which would decrease as the vertical permeability decreases. The fluid velocity varies from 1000 to $10 \mathrm{~m} / \mathrm{yr}$ with a low permeability anisotropy $\left(k_{\mathrm{h}}: k_{\mathrm{v}}=1\right)$. It varies from 100 to $1 \mathrm{~m} / \mathrm{yr}$ with a moderate permeability anisotropy $\left(k_{\mathrm{h}}: k_{\mathrm{v}}=10\right)$. It will decrease further, varying from 10 to $0.1 \mathrm{~m} / \mathrm{yr}$, while the permeability anisotropy increases further $\left(k_{\mathrm{h}}: k_{\mathrm{v}}=100\right)$.

By comparing the permeability in different scenarios, the permeability heterogeneity of host rock mainly influences the fluid velocity but exerts few impacts on general pattern of fluid flow. In addition, the well-cemented or strongly recrystallized grainstones (scenarios I and II) could have reduced the fluid velocity $10-100$ times in comparison to the grainstones with a little early cements (scenario III) (Figure 11).

4.2. Temperature Patterns. Similar to the fluid flow pattern, formation temperature is also controlled by permeability anisotropy (Figure 12). In the context of low permeability anisotropy $\left(k_{\mathrm{h}}: k_{\mathrm{v}}=1\right)$ and high fluid velocity, the formation temperature is dominated by fluid convective heat transfer, which would decrease significantly in the front zone of hydrothermal invasion and generate thermal anomalies of $50^{\circ} \mathrm{C}$ higher than normal temperature (Figures 12(a), 12(d), and $12(\mathrm{~g})$ ). In contrast, in the context of moderate permeability anisotropy, the thermal anomalies would wane apparently, only giving rise to an increase on formation temperature of $1-10^{\circ} \mathrm{C}$ (Figures 12(b), 12(e), and 12(h)). Furthermore, as permeability anisotropy is enhanced further $\left(k_{\mathrm{h}}: k_{\mathrm{v}}=100\right)$, vanishingly weak thermal anomaly is observed probably as 


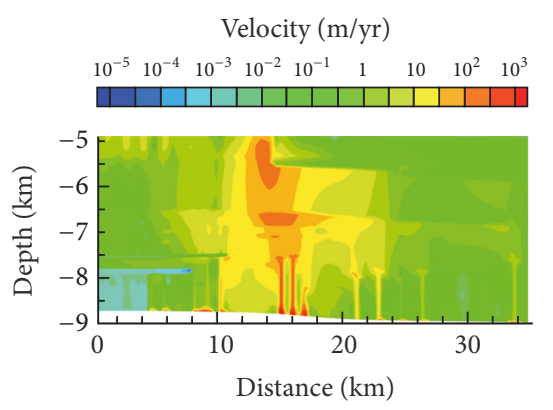

(a)

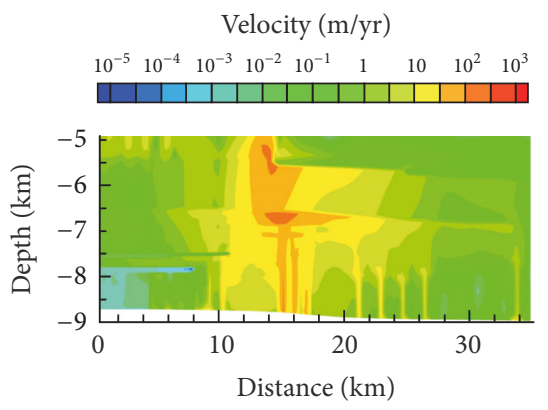

(d)

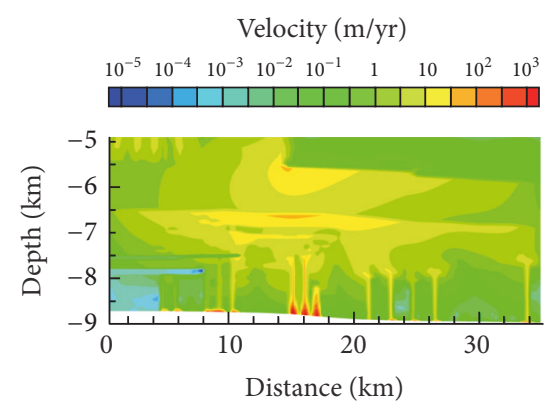

(b)

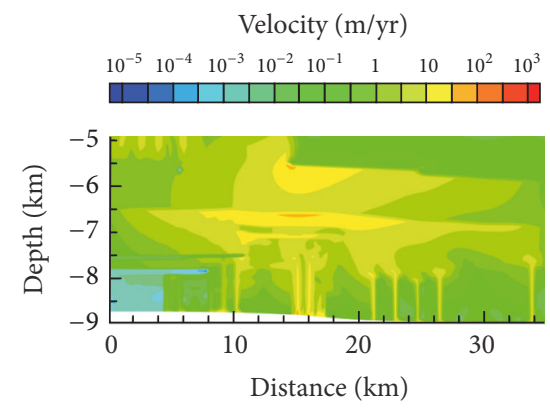

(e)

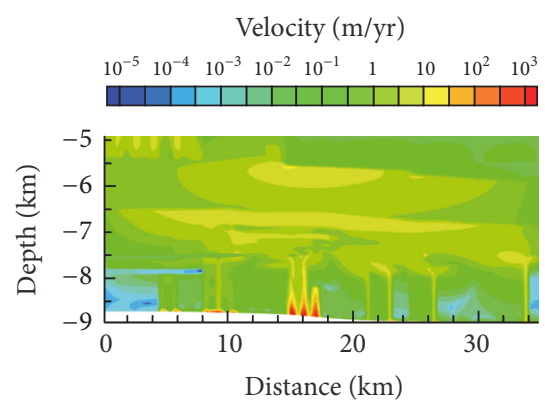

(c)

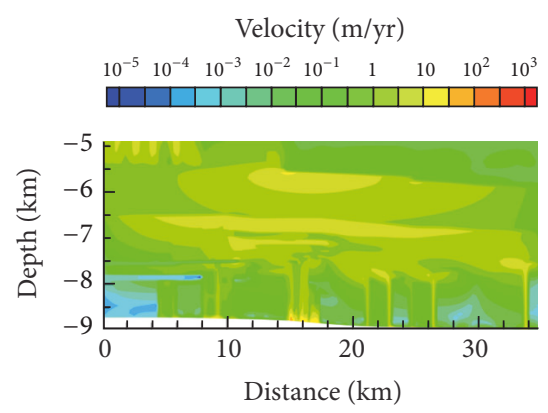

(f)

FIGURE 13: The fluid velocity for Scenario I with fault permeability of $1 \times 10^{-13} \mathrm{~m}^{2}:$ (a) $k_{\mathrm{h}}: k_{\mathrm{v}}=1$, (b) $k_{\mathrm{h}}: k_{\mathrm{v}}=10$, and (c) $k_{\mathrm{h}}: k_{\mathrm{v}}=100$ and fault permeability of $1 \times 10^{-15} \mathrm{~m}^{2}:$ (d) $k_{\mathrm{h}}: k_{\mathrm{v}}=1$, (e) $k_{\mathrm{h}}: k_{\mathrm{v}}=10$, and (f) $k_{\mathrm{h}}: k_{\mathrm{v}}=100$.

a result of enhanced heat conduction in rocks (Figures 12(c), $12(\mathrm{f})$, and 12(i)).

Besides the permeability anisotropy, temperature patterns can also be influenced by the permeability heterogeneity because this heterogeneity can increase the fluid velocity and enhance the convective heat. In scenario III, if the shoaldeposited grainstones were rarely cemented with high porosity and permeability during the Early Permian, a thermal anomaly of about $10-30^{\circ} \mathrm{C}$ could have been induced in these sediments relative to well-cemented grainstones (scenarios I and II) around the well TS1.

4.3. Influence of Fault Permeability. Taking scenario I as an example, the sensitivity of fault permeability to the modeling results was tested. The fault permeability varies from the baseline value $\left(1 \times 10^{-14} \mathrm{~m}^{2}\right)$ to the values by plus or minus one order of magnitude relative to the consistent permeability of country rocks. The modeling results show vanishingly small influences of fault permeability on the fluid velocity and temperature patterns in comparison to the baseline modeling (Figures 13 and 14).

The fluid velocity and temperature patterns changed slightly in the condition with a low permeability anisotropy $\left(k_{\mathrm{h}}: k_{\mathrm{v}}=1\right)$ (Figures 13(a), 13(d), 14(a), and 14(d)) which have the highest vertical permeability and strong fluid transport ability. For a comparison, in the conditions with moderate and large permeability anisotropies, the fault permeability almost exerts no influence on the simulation results.

4.4. Spatial Patterns of Dolomite Dissolution. Our simulation on dolomite dissolution runs for three scenarios for a time interval of $10 \mathrm{Ma}$ (Figure 15) in view of long-lasting compression from the north by the collision of Tarim block and Tianshan accretionary complex during the Late CarboniferousEarly Permian ( 306-270 Ma) [31-33]. The simulation results indicate that the porosity can be produced continuously by dissolution in dolomite rocks within fault zones due to a higher fluid velocity there. The dolomite dissolution generally occurred in the hydrothermal invasion zones of the wallrock. In addition, the development of porosity is also controlled by the permeability anisotropy. For a low permeability anisotropy $\left(k_{\mathrm{h}}: k_{\mathrm{v}}=1\right)$, a large amount of dissolved porosity, with a maximum up to $5 \%$, occur in the upper part of wallrock and gradually decrease downward (Figures 15(a), 15(d), and $15(\mathrm{~g})$ ). Combined with fluid velocity and temperature patterns together, dissolved porosity was produced mainly in the place where formation temperature decreases significantly.

In contrast, with a moderate permeability anisotropy $\left(k_{\mathrm{h}}: k_{\mathrm{v}}=10\right)$, the dissolved porosity, although decreasing to ca. $2 \%$, takes place more widely (Figures 15(b), 15(e), and $15(\mathrm{~h})$ ). In view of fluid velocity and temperature patterns together, the porosity occurs mainly in the place where fluids flow rapidly as in scenarios I and II. But in scenario III, the dissolved porosity is controlled mainly by the temperature pattern due to enhanced thermal anomaly.

As permeability anisotropy increases further $\left(k_{\mathrm{h}}: k_{\mathrm{v}}=\right.$ $100)$, dissolution on dolomites is dramatically reduced for the simulation time interval. In the most part of the model domain, less than $0.2 \%$ of dissolved porosity can be generated, even in local places where more pore or vuggy spaces (ca. 0.3-0.5\%) can be dissolved (Figures 15(c), 15(f), and 15(i)). 


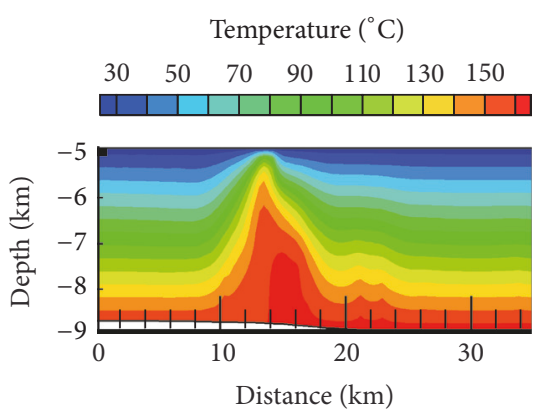

(a)

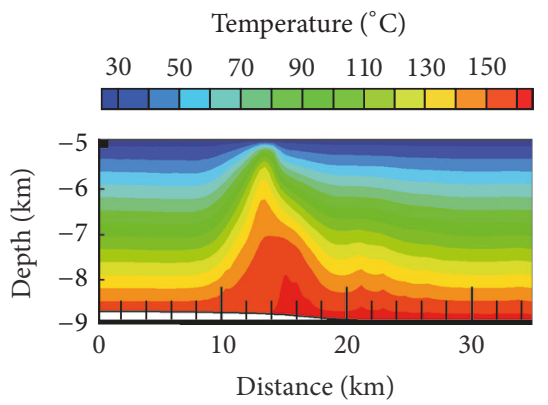

(d)

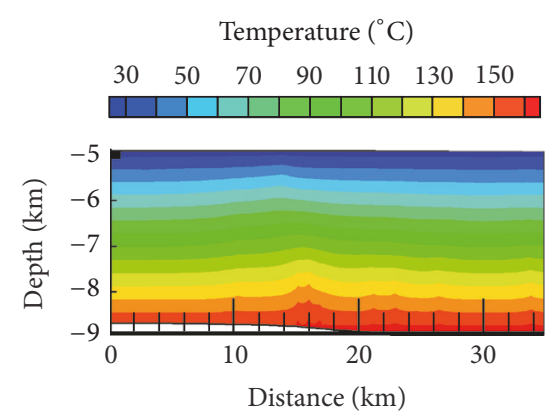

(b)

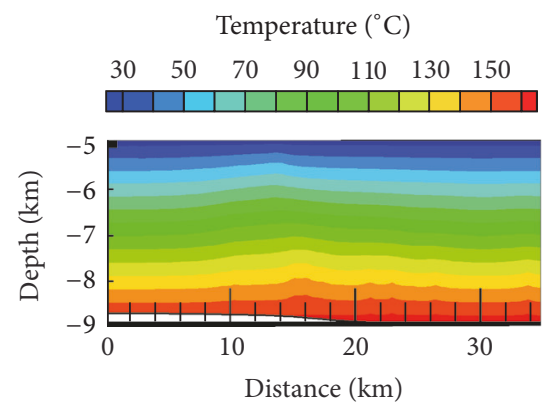

(e)

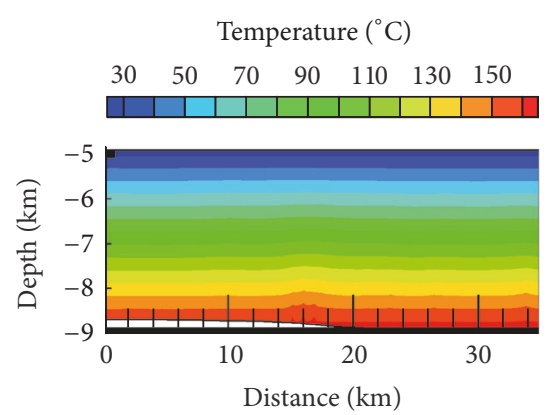

(c)

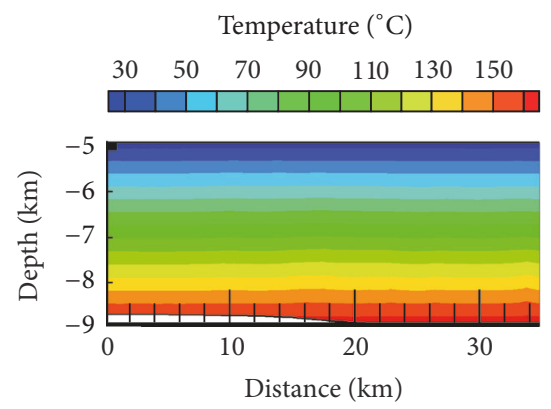

(f)

FIGURE 14: The temperature patterns for Scenario I with fault permeability of $1 \times 10^{-13} \mathrm{~m}^{2}:$ (a) $k_{\mathrm{h}}: k_{\mathrm{v}}=1$, (b) $k_{\mathrm{h}}: k_{\mathrm{v}}=10$, and (c) $k_{\mathrm{h}}: k_{\mathrm{v}}=100$ and fault permeability of $1 \times 10^{-15} \mathrm{~m}^{2}:(\mathrm{d}) k_{\mathrm{h}}: k_{\mathrm{v}}=1$, (e) $k_{\mathrm{h}}: k_{\mathrm{v}}=10$, and (f) $k_{\mathrm{h}}: k_{\mathrm{v}}=100$.

This is mainly because the fluids dominantly flow laterally along the isotherms of temperature. As a result, the dissolving capacity of fluid is drawn down rapidly in response to temperature decrease. In addition, the fluid velocity has also played a role in dolomite dissolution. The fluid velocity has slightly increased from scenarios I to III (Figures 11(c), 11(f), and 11(i)), increasing the dissolved porosity to some extent (Figures 15(c), 15(f), and 15(i)). However, the fluid velocity only plays a subordinate role in the formation of dissolved porosity in comparison to the isothermal flow which causes one-order magnitude reduction of porosity in contrast to the high vertical permeability $\left(k_{\mathrm{h}}: k_{\mathrm{v}}=10\right)$ (Figures 15(b), 15(e), and $15(\mathrm{~h})$ ).

\section{Discussion}

This study aimed to investigate the dissolution upon the dolomites at great depth within the fault zones induced by the upflowing hydrothermal fluids around the deeply penetrated well TS1 and adjacent area in the North Uplift of Tarim Basin. This could provide an alternative insight on processes and controls of burial and/or hydrothermal dissolution on dolomites, porosity generation and preservation in deeply buried fault-related carbonate reservoirs, facilitating a better understanding for the formation of deeply buried carbonate reservoirs, and more efficient prediction and exploration of hydrocarbon to greater depths.

5.1. Deep Burial/Hydrothermal Dissolution of Carbonates. The burial dissolution of carbonates is still a controversial topic for reservoir geologists [50]. Many authors have proposed that deep-burial dissolution of carbonate could has been induced by a series of acidic fluids, such as $\mathrm{CO}_{2}-\mathrm{H}_{2} \mathrm{~S}$ and organic acidic-rich fluids, which could be produced by different geological process. The strong large igneous province (LIP) activity in the Tarim Basin during the Early Permian could have caused intense thermal anomaly $[26,41]$, which in turn could have promoted organic matter maturation, organic acid production, and thermochemical sulfate reduction in the Cambrian strata $[48,51]$. As a result, the acidic anions may have increased in the hydrothermal fluids by mixing with the formation and magmatic-originated fluids at depth. However, Ehrenberg et al. [50] pointed out that the dissolving fluids could quickly reach equilibrium with carbonate minerals due to the rapid kinetic dissolution of carbonate minerals. In this case, acid-induced dissolution on carbonates could have only occurred locally in the place where the acidic fluid was generated or injected.

Many researchers proposed that widespread dissolution of carbonates may have been caused by retrograde dissolution during the course of temperature falling $[8,43]$. As fluids from depths flow upward, fluid temperature decreases gradually. In this condition, the original carbonate-saturated fluids then tend to be undersaturated relative to carbonate minerals, thereby causing carbonate dissolution. In burial condition, the basinal fluid undoubtedly has a higher temperature, which will lead to a faster rate of chemical reaction, but characterizes a fairly slow velocity relative to the near surface conditions. These factors make the formation fluids quickly reach the equilibrium with carbonate minerals. In this light, 


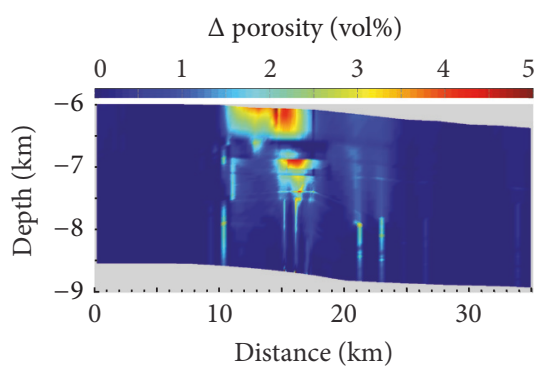

(a)

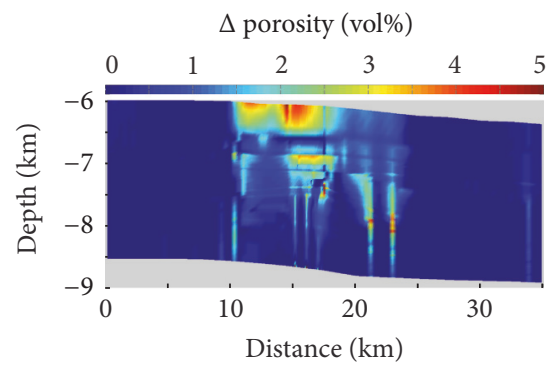

(d)

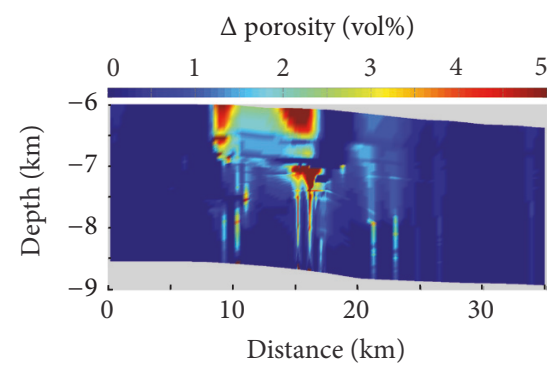

(g)

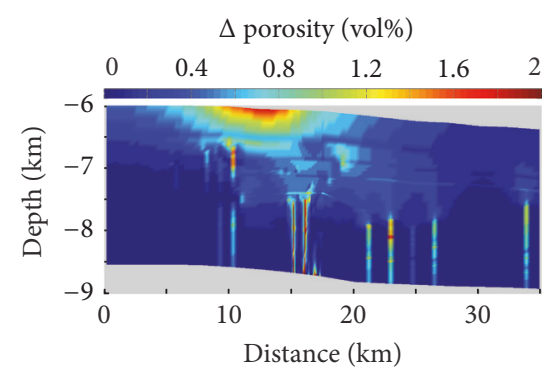

(b)

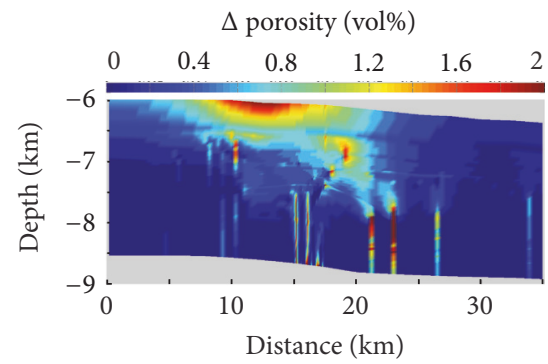

(e)

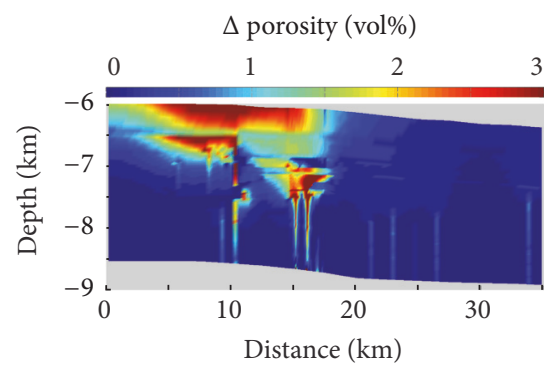

(h)

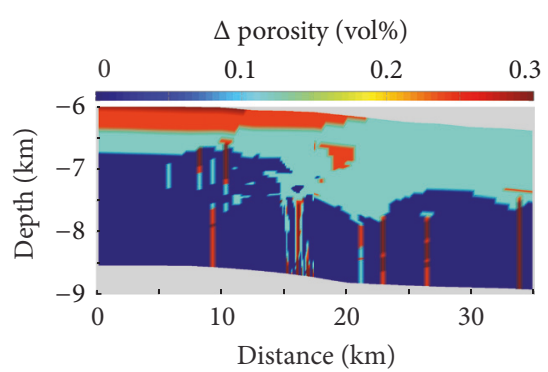

(c)

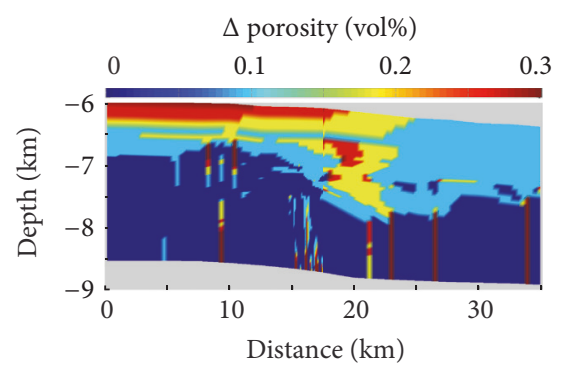

(f)

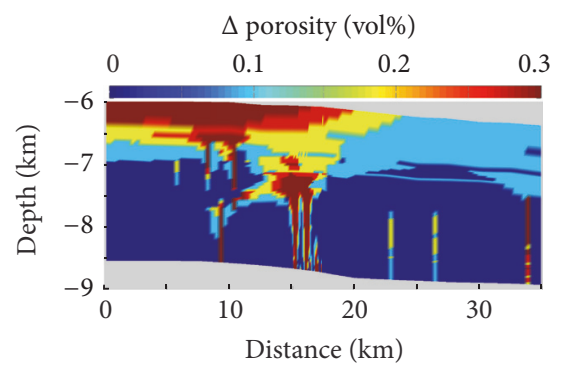

(i)

FIGURE 15: The dolomite dissolution patterns simulated for an interval of $10 \mathrm{Ma}$ for Scenario I: (a) $k_{\mathrm{h}}: k_{\mathrm{v}}=1$, (b) $k_{\mathrm{h}}: k_{\mathrm{v}}=10$, and (c) $k_{\mathrm{h}}: k_{\mathrm{v}}=100$; Scenario II: (d) $k_{\mathrm{h}}: k_{\mathrm{v}}=1$, (e) $k_{\mathrm{h}}: k_{\mathrm{v}}=10$, and (f) $k_{\mathrm{h}}: k_{\mathrm{v}}=100$; and Scenario III: (g) $k_{\mathrm{h}}: k_{\mathrm{v}}=1$, (h) $k_{\mathrm{h}}: k_{\mathrm{v}}=10$, and (i) $k_{\mathrm{h}}: k_{\mathrm{v}}=100$. The plotting area is referred to the model domain below dashed lines in Figure 11 which is mainly composed of dolomite formation.

we believe that retrograde dissolution may have played the most important role in carbonate dissolution during deep burial. Under this circumstance, in view of the fast reaction rate and retrograde dissolution behaviour, substantial dissolution and subsequent pore development require a much high volume of fluid relative to the host carbonate rock which is favoured in the connected pore spaces such as open fracture networks.

This is generally consistent with our observation on the deeply buried Cambrian dolomite rocks in which the intensive dissolution and abundant vuggy spaces occurred mainly in connected fracture networks and pores system close to the fault zone around the bottom of penetrated borehole TS1 (Figure $8(\mathrm{~b})$ ). In contrast, dolomite (mostly saddle dolomite) precipitation in the vuggy and fracture spaces and matrix recrystallization in the Mid-upper Cambrian dolomites were likely associated with the closed (or semiclosed) pore systems which were generally more distal to the fault zone.

5.2. Importance of the Wall-Rock Vertical Permeability. The modeling results have demonstrated that wall-rock permeability exerts a fundamental control on the fluid flow, formation temperature, and dolomite dissolution as well. The permeability anisotropy is the most important parameter that controls the general patterns of fluid flow, fluid velocity and temperature. In comparison, the permeability heterogeneity could have mainly influenced the fluid velocity and temperature patterns.

Despite the fast rate of carbonate dissolution, our simulation results suggest that the burial or hydrothermal dissolution of carbonates at depths was not simply a transportlimited process; rather it could be an integrative effect of both fluid velocity and temperature gradients. With a high vertical permeability of wall-rock $\left(k_{\mathrm{h}}: k_{\mathrm{v}}=1\right)$ in the fracture/fault zone, although the higher-speed fluids could have delivered more ample dissolved matter, the stronger thermal anomaly around the area of well TS1 only with a slight temperature decrease (Figures 12(a), 12(d), and 12(g)) seemingly limited the dolomite dissolution. In contrast, the hydrothermal front with a maximum decrease in temperature led to substantial dissolution on dolomites (Figures 15(a), 15(d), and 15(g)). As the vertical permeability decreased, the fluid velocity could 
have reduced accordingly through which the dissolution tended to be a transport-limited process (Figures 15(b), 15(e), and $15(\mathrm{~h}))$. In this case, the distribution of dissolved porosity may have mirrored the variation of fluid velocity (Figures 11(b), 11(e), and 11(h)).

As vertical permeability further decrease $\left(k_{\mathrm{h}}: k_{\mathrm{v}}=100\right)$, the dissolved porosity is reduced significantly (Figures 15(c), 15(f), and 15(i)) due to isothermal flowing (Figures 11(c), 11(f), and 11(i)). Therefore, the deeply buried carbonate reservoir was unlikely favoured by the hydrothermal dissolution if the vertical permeability of wall-rocks was too low.

5.3. Influence of Fault Zone Permeability. The sensitivity test indicates that the fault permeability has a little influence on burial/hydrothermal dissolution. Since the internal architecture of fault zone is too complicated, it is difficult to estimate permeability variations across the fault zone $[47,52,53]$. Alternatively, this research implies that faultrelated hydrothermal dissolution on dolomite rocks could be potentially predicted by studying the permeability pattern of the wall-rock.

With progressive burial of sediments, the geological fluid would have stagnated in the deep part of basins due to the dramatic decrease of rock permeability $[54,55]$. However, tectonic activity accompanying with increasing fault permeability could have enhanced crossing-stratal fluid flow and basin-scale deep circulation of geological fluids $[54,55]$. In general, after seismic rupturing and subsequent abrupt permeability increase, the permeability in fault zones will gradually decrease with times [14, 47] which would influence the hydrothermal fluid flow as well. Our simulations have tested the influence of this process on the fluid flow, temperature pattern, and induced carbonate dissolution. The modeling results indicate that, as the fault permeability decreases, burial dissolution can still persist onwards in view of the small influences of fault permeability on the fluid velocity and temperature patterns (Figures 13 and 14) which will control the distribution of dissolved porosity.

5.4. Function of Cap Aquitards and Internal Aquifers. The hydrothermal dissolution mainly occurred in dolomites deposited on platform margin but did not occur in dolomites of platform interior and slope environments (Figure 15), probably resulting from the presence of low permeable cap aquitards which may have prevented vertical crossingformational flowing (Figure 11). This implies that occurrence of low permeable cap aquitards is an important indicator for predicting of deeply buried carbonate reservoirs.

The internal aquifers in which fluids mainly flow horizontally are not favourable for burial/hydrothermal dissolution due to a constant temperature if they are laid horizontally during burial. The unconformities which have high horizontal permeability were generally considered as important exploration targets for carbonate reservoirs $[1,2]$. However, the modeling result suggests that the porosity along the horizontally buried unconformity surfaces within carbonate successions, although acting as internal aquifers, may have not been enhanced necessarily by hydrothermal dissolution due to insignificant temperature drawdown.
5.5. Predictions of Deep/Ultradeep Carbonate Reservoirs. As the burial depth increases, the primary porosity of carbonates will be significantly lost due to the mechanical and chemical compaction [3,5] (Figures 4(b) and 8(a)), thus burial/hydrothermal dissolution could have played a critical role in pore generation, preservation, and subsequent reservoir development.

Our modeling demonstrates the importance of vertical permeability of wall-rocks on burial or hydrothermal dissolution. Those dolomites (or carbonates), as if tensional or transtensional fractures (joints) were extensively developed, would have a higher potential to develop dissolution vugs or cavities, facilitating formation of deeply buried carbonate reservoirs (Figure 15). Moreover, studies on the style and mechanism of fracturing and/or faulting would be much helpful for better understanding for the flow patterns and pathway of basinal thermal fluids. In turn, if integrated with reactive transport modeling, the deeply buried carbonate reservoirs could be more precisely predicted.

\section{Conclusions}

The Cambrian dolomite strata penetrated by the deep well TS1 in the northern Tarim Basin are characterized by microbial reefs (or buildups) deposited on the platform margin. Four types of dolomite texture are identified, including two types of matrix dolomites, (1) fabric-retentive dolomite (Md1) and (2) fabric-obliterated nonplanar dolomite ( $\mathrm{Md} 2$ ), and two types of cement dolomite, (3) medium to coarsely crystalline planar-s (e) dolomite (Cd1) and (4) coarsely crystalline nonplanar saddle dolomite $(\mathrm{Cd} 2)$. The dolomites were subject to complicated diagenetic events and alteration, such as early dolomitization, compaction, fracturing, and hydrothermal dissolution and alteration (precipitation and recrystallization).

In the northern Tarim Basin where the well TS1 is located, a series of high-angle X-shaped (wrench) fault complex dominate the dolomite strata with subordinate N-S and E$\mathrm{W}$ trending fault series; they cut off the Cambrian base and partially extend into the Ordovician. These fault/fracture complexes may have been formed during the Late Ordovician while the Tarim plate was subducted northward beneath the Central Tianshan arc and was further reactivated while it was finally collided with the Tianshan arc accretionary complex (collage) during the Permian. A series of X-shaped wrench fracture system also extensively occur in the cored dolomite samples particularly near the main fault zones.

The dissolved vuggy pores preferentially take place along the fractures particularly in the lower part of well TS1 where they are also less plugged by dolomite cements. All these features demonstrate the interaction of fracture- or faultchanneled upward-flowing hydrothermal fluids with the host dolomites through which intense dissolution occurred preferentially in the lower part of dolomites having been penetrated. The enhanced hydrothermal activity was likely linked to the LIP activity in the Tarim block during the Early Permian.

The reactive transport modeling demonstrates the importance of wall-rock permeability on fluid and temperature 
patterns, particularly the vertical permeability dependent on the connectedness of fractures; it could have further controlled the spatial distribution of dissolved vuggy porosity. In contrast, the fault permeability has little influence on the distribution of dissolved porosity.

The hydrothermal dissolution mainly occurred in platform margin dolomites penetrated by the high-angle fault series and was fairly weak in platform interior and slopebasinal dolomites due to the presence of cap aquitards (evaporites and shales) which could have prohibited upward flowing of fluid. The presence of internal aquifers, such as horizontally buried unconformity surface, did not necessarily enhance the hydrothermal dissolution.

This study provides an integrated approach with geological analysis and reactive transport modeling to unveil the process of hydrothermal dissolution on dolomite rocks associated with faults or fractures from a deep-penetrated well TS1 in northern Tarim Basin; this would further improve our understanding for the development and distribution of deeply buried carbonate reservoirs.

\section{Conflicts of Interest}

The authors declare that they have no conflicts of interest.

\section{Acknowledgments}

This study was supported by the National Natural Science Foundation of China (Grant no. U1663209) and National Science and Technology Priority Special Project of China (Grant no. 2011ZX0500803). The authors are much grateful to the reviewer (Y. Xiao) for his positive comments on this study.

\section{References}

[1] P. O. Roehl and P. W. Choquette, Carbonate Petroleum Reservoirs, Springer, Berlin, Germany, 1985.

[2] J. Garland, J. Neilson, S. E. Laubach, and K. J. Whidden, "Advances in carbonate exploration and reservoir analysis," Geological Society Special Publication, vol. 370, no. 1, pp. 1-15, 2012.

[3] J. W. Schmoker and R. B. Halley, "Carbonate porosity versus depth: a predictable relation for south Florida," American Association of Petroleum Geologists Bulletin, vol. 66, no. 12, pp. 25612570, 1982.

[4] S. N. Ehrenberg, G. P. Eberli, M. Keramati, and S. A. Moallemi, "Porosity-permeability relationships in interlayered limestonedolostone reservoirs," AAPG Bulletin, vol. 90, no. 1, pp. 91-114, 2006.

[5] D. Zhu, Q. Meng, Z. Jin, Q. Liu, and W. Hu, "Formation mechanism of deep Cambrian dolomite reservoirs in the Tarim basin, northwestern China," Marine and Petroleum Geology, vol. 59, pp. 232-244, 2015.

[6] F. F. Whitaker, P. L. Smart, and G. D. Jones, "Dolomitization: from conceptual to numerical models," Geological Society Special Publication, vol. 235, pp. 99-139, 2004.

[7] F. F. Whitaker and Y. Xiao, "Reactive transport modeling of early burial dolomitization of carbonate platforms by geothermal convection," AAPG Bulletin, vol. 94, no. 6, pp. 889-917, 2010.
[8] G. D. Jones and Y. Xiao, "Geothermal convection in South Atlantic subsalt lacustrine carbonates: developing diagenesis and reservoir quality predictive concepts with reactive transport models," AAPG Bulletin, vol. 97, no. 8, pp. 1249-1271, 2013.

[9] T. Xu, E. Sonnenthal, N. Spycher, and K. Pruess, TOUGHREACT User's Guide: A Simulation Program for Non-Isothermal Multiphase Reactive Geochemical Transport in Variable Saturated Geologic Media, Lawrence Berkeley National Laboratory, Berkeley, Calif, USA, 2008.

[10] G. D. Jones and Y. Xiao, "Dolomitization, anhydrite cementation, and porosity evolution in a reflux system: insights from reactive transport models," AAPG Bulletin, vol. 89, no. 5, pp. 577-601, 2005.

[11] P. Lu and D. Cantrell, "Reactive transport modelling of reflux dolomitization in the Arab-D reservoir, Ghawar field, Saudi Arabia," Sedimentology, vol. 63, no. 4, pp. 865-892, 2016.

[12] B. Garcia-Fresca, F. Jerry Lucia, J. M. Sharp Jr., and C. Kerans, "Outcrop-constrained hydrogeological simulations of brine reflux and early dolomitization of the Permian San Andres Formation," AAPG Bulletin, vol. 96, no. 9, pp. 1757-1781, 2012.

[13] Y. Xiao, G. D. Jones, F. F. Whitaker et al., "Fundamental approaches to dolomitization and carbonate diagenesis in different hydrogeological systems and the impact on reservoir quality distribution," in Proceedings of the sixth International Petroleum Technology Conference (IPTC '13), pp. 1164-1179, Beijing, China, March 2013.

[14] G. R. Davies and L. B. Smith Jr., "Structurally controlled hydrothermal dolomite reservoir facies: an overview," AAPG Bulletin, vol. 90, no. 11, pp. 1641-1690, 2006.

[15] H. R. Qing and E. W. Mountjoy, "Formation of coarsely crystalline, hydrothermal dolomite reservoirs in the Presquile Barrier, Western Canada Sedimentary Basin," AAPG Bulletin, vol. 78, no. 1, pp. 55-77, 1994.

[16] H. G. Machel, "Concepts and models of dolomitization: a critical reappraisal," in The Geometry and Petrogenesis of Dolomite Hydrocarbon Reservoirs, vol. 235, pp. 7-63, Geological Society London Special Publications, London, UK, 2004.

[17] Z. Gao, T. Fan, Z. Jiao, and Y. Li, "The structural types and depositional characteristics of carbonate platform in the cambrianordovician of tarim basin," Acta Sedimentologica Sinica, vol. 24, no. 1, pp. 19-27, 2006.

[18] Z. Zhao, Y. Zhang, M. Pan, W. U. Xingning, and W. Pan, "Cambrian sequence stratigraphic framework in Tarim Basin," Geological Review, vol. 56, pp. 609-620, 2010.

[19] Z. Feng, Z. Bao, M. Wu, Z. Jin, and X. Shi, "Lithofacies palaeogeography of the Cambrian in Tarim area," Journal of Palaeogeography, vol. 8, pp. 427-439, 2006.

[20] Z. Feng, Z. Bao, M. Wu, Z. Jin, X. Shi, and A. R. Luo, "Lithofacies palaeogeography of the Ordovician in Tarim area," Journal of Palaeogeography, vol. 9, no. 5, pp. 447-460, 2007.

[21] Z. Zhao, W. Pan, L. Zhang, S. Deng, and Z. Huang, "Sequence stratigraphy in the ordovician in the Tarim Basin," Geotectonica et Metallogenia, vol. 33, no. 1, pp. 175-188, 2009.

[22] Z. Jin, Y. Zhang, and S. Chen, "Wave tectono-sedimentary processes in Tarim basin," Science in China, Series D: Earth Sciences, vol. 48, no. 11, pp. 1949-1959, 2005.

[23] Z. L. He, H. B. Mao, X. F. Zhou, M. Cong, and X. Y. She, "Complex petroleum system and multicycle basin in Tarim," Oil \& Gas Geology, vol. 21, no. 3, pp. 207-213, 2000.

[24] Y. Kang and Z. Kang, "Tectonic evolution and oil and gas of Tarim basin," Journal of Southeast Asian Earth Sciences, vol. 13, no. 3-5, pp. 317-325, 1996. 
[25] C. Guo, D. Chen, H. Qing et al., "Multiple dolomitization and later hydrothermal alteration on the Upper Cambrian-Lower Ordovician carbonates in the northern Tarim Basin, China," Marine and Petroleum Geology, vol. 72, pp. 295-316, 2016.

[26] Z. Jin, D. Zhu, W. Hu, X. Zhang, Y. Wang, and X. Yan, “Geological and geochemical signatures of hydrothermal activity and their influence on carbonate reservoir beds in the Tarim Basin," Acta Geologica Sinica, vol. 80, no. 2, pp. 245-253, 2006.

[27] S. Dong, D. Chen, H. Qing et al., "Hydrothermal alteration of dolostones in the Lower Ordovician, Tarim Basin, NW China: multiple constraints from petrology, isotope geochemistry and fluid inclusion microthermometry," Marine and Petroleum Geology, vol. 46, pp. 270-286, 2013.

[28] H. Chen, S. Yang, C. Dong et al., "Geological thermal events in Tarim Basin," Chinese Science Bulletin, vol. 42, no. 7, pp. 580584, 1997.

[29] S. Dong, D. Chen, H. Qing, M. Jiang, and X. Zhou, "In situ stable isotopic constraints on dolomitizing fluids for the hydrothermally-originated saddle dolomites at Keping, Tarim Basin," Chinese Science Bulletin, vol. 58, no. 23, pp. 2877-2882, 2013.

[30] S. Zou, Z. Li, Z. Ren et al., "U-Pb dating and Hf isotopic compositions of detrital zircons from permian sedimentary rocks in keping area of Tarim Basin, Xinjiang, China: constraints on geological evolution of tarim block," Acta Petrologica Sinica, vol. 29, no. 10, pp. 3369-3388, 2013.

[31] D. Zhou, S. A. Graham, E. Z. Chang, B. Wang, and B. Hacker, "Paleozoic amalgamation of the Chinese Tian Sahn: evidence from a trnsect along the Dushanzi-Kuqa Highway," in Paleozoic and Mesozoic Tectonic Evolution of Central and Eastern Asia: From Continetal Assembly to Intracontinental Deformation, M. S. Hendix and G. A. Davis, Eds., vol. 194 of Geological Society of America Memoirs, pp. 23-46, Geological Society of America, 2001.

[32] W. Xiao, C. Han, C. Yuan et al., "Middle Cambrian to Permian subduction-related accretionary orogenesis of Northern Xinjiang, NW China: implications for the tectonic evolution of central Asia," Journal of Asian Earth Sciences, vol. 32, no. 2-4, pp. 102-117, 2008.

[33] W.-J. Xiao, L.-C. Zhang, K.-Z. Qin, S. Sun, and J.-L. Li, "Paleozoic accretionary and collisional tectonics of the Eastern Tianshan (China): implications for the continental growth of central Asia," American Journal of Science, vol. 304, no. 4, pp. 370-395, 2004.

[34] R. Caputo, "Why joints are more abundant than faults. A conceptual model to estimate their ratio in layered carbonate rocks," Journal of Structural Geology, vol. 32, no. 9, pp. 1257-1270, 2010.

[35] P. Zhang, G. Hou, W. Pan et al., "Research on the effectiveness of fractures in Sinian-Cambrian dolomite reservoir in Tarim Basin," Acta Scientiarum Naturalium Universitatis Pekinensis, vol. 49, no. 6, pp. 993-1001, 2013.

[36] C. A. Underwood, M. L. Cooke, J. A. Simo, and M. A. Muldoon, "Stratigraphic controls on vertical fracture patterns in Silurian dolomite, northeastern Wisconsin," AAPG Bulletin, vol. 87, no. 1, pp. 121-142, 2003.

[37] D. Ye, "Deep dissolution of Cambrian-Odovician carbonates in the Northern Tarin Basin," Acta Sedimentologica Sinica, vol. 12, pp. 66-71, 1994.

[38] L. Jiang, W. Pan, C. Cai et al., "Fluid mixing induced by hydrothermal activity in the ordovician carbonates in Tarim Basin, China," Geofluids, vol. 15, no. 3, pp. 483-498, 2015.

[39] X. You, S. Sun, J. Zhu, Q. Li, W. Hu, and H. Dong, "Microbially mediated dolomite in Cambrian stromatolites from the Tarim
Basin, north-west China: implications for the role of organic substrate on dolomite precipitation," Terra Nova, vol. 25, no. 5, pp. 387-395, 2013.

[40] G.-Y. Wu, Y.-J. Li, Y.-L. Liu, Y. Zhao, and H. Li, "Petrochemistry and regional tectonic implications of Permian-Early Triassic volcanic rocks in the Tabei rise, Tarim basin," Journal of Mineralogy and Petrology, vol. 32, no. 4, pp. 21-30, 2012.

[41] Y.-G. Xu, X. Wei, Z.-Y. Luo, H.-Q. Liu, and J. Cao, “The Early Permian Tarim Large Igneous Province: main characteristics and a plume incubation model," Lithos, vol. 204, pp. 20-35, 2014.

[42] F. J. Lucia, "Rock-fabric/petrophysical classification of carbonate pore space for reservoir characterization," American Association of Petroleum Geologists Bulletin, vol. 79, no. 9, pp. 1275-1300, 1995.

[43] G. D. Jones and Y. Xiao, "Geothermal convection in the Tengiz carbonate platform, Kazakhstan: reactive transport models of diagenesis and reservoir quality," AAPG Bulletin, vol. 90, no. 8, pp. 1251-1272, 2006.

[44] W. J. Harrison and L. L. Summa, "Paleohydrology of the Gulf of Mexico basin," American Journal of Science, vol. 291, no. 2, pp. 109-176, 1991.

[45] C. E. Manning and S. E. Ingebritsen, "Permeability of the continental crust: implications of geothermal data and metamorphic systems," Reviews of Geophysics, vol. 37, no. 1, pp. 127-150, 1999.

[46] V. F. Bense, T. Gleeson, S. E. Loveless, O. Bour, and J. Scibek, "Fault zone hydrogeology," Earth-Science Reviews, vol. 127, no. 2, pp. 171-192, 2013.

[47] S. E. Ingebritsen and C. E. Manning, "Permeability of the continental crust: dynamic variations inferred from seismicity and metamorphism," Geofluids, vol. 10, no. 1-2, pp. 193-205, 2010.

[48] C. Cai, S. G. Franks, and P. Aagaard, "Origin and migration of brines from Paleozoic strata in Central Tarim, China: constraints from ${ }^{87} \mathrm{Sr} /{ }^{86} \mathrm{Sr}, \delta \mathrm{d}, \delta^{18} \mathrm{O}$ and water chemistry," Applied Geochemistry, vol. 16, no. 9-10, pp. 1269-1284, 2001.

[49] J. L. Palandri and Y. K. Kharaka, "A compilation of rate parameters of water-mineral interaction kinetics for application to geochemical modeling," U.S. Geological Survey Open File Report 2004-1068, 2004.

[50] S. N. Ehrenberg, O. Walderhaug, and K. Bjerlykke, "Carbonate porosity creation by mesogenetic dissolution: reality or illusion?" AAPG Bulletin, vol. 96, no. 2, pp. 217-225, 2012.

[51] C. Cai, K. Li, H. Li, and B. Zhang, "Evidence for cross formational hot brine flow from integrated ${ }^{87} \mathrm{Sr} /{ }^{86} \mathrm{Sr}$, REE and fluid inclusions of the Ordovician veins in Central Tarim, China," Applied Geochemistry, vol. 23, no. 8, pp. 2226-2235, 2008.

[52] M. Manga, I. Beresnev, E. E. Brodsky et al., "Changes in permeability caused by transient stresses: field observations, experiments, and mechanisms," Reviews of Geophysics, vol. 50, no. 2, Article ID RG2004, 2012.

[53] T. M. Mitchell and D. R. Faulkner, "Towards quantifying the matrix permeability of fault damage zones in low porosity rocks," Earth and Planetary Science Letters, vol. 339-340, pp. 2431, 2012.

[54] G. Garven, "Continental-scale groundwater flow and geologic processes," Annual Review of Earth Planetary Sciences, vol. 23, no. 1, pp. 89-118, 2003.

[55] G. Garven and R. A. Freeze, "Theoretical analysis of the role of groundwater flow in the genesis of stratabound ore deposits. 1. Mathematical and numerical model," American Journal of Science, vol. 284, no. 10, pp. 1085-1124, 1984. 

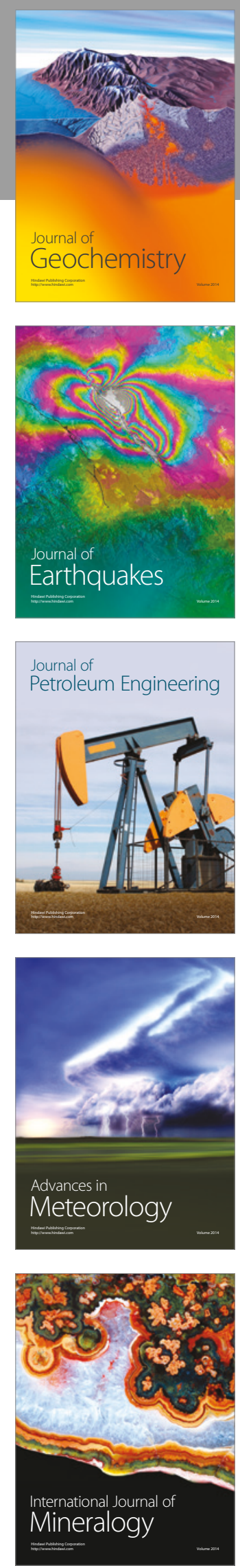
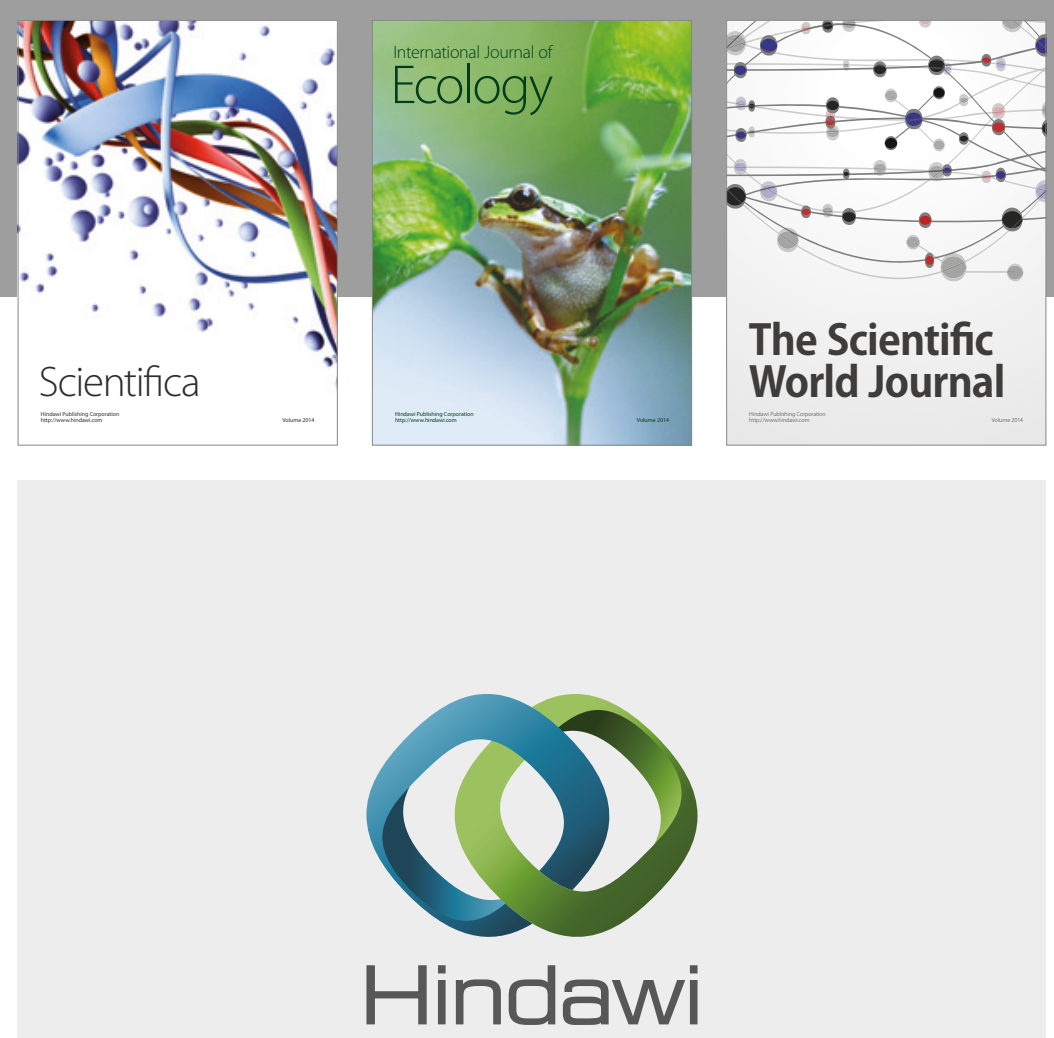

Submit your manuscripts at

https://www.hindawi.com
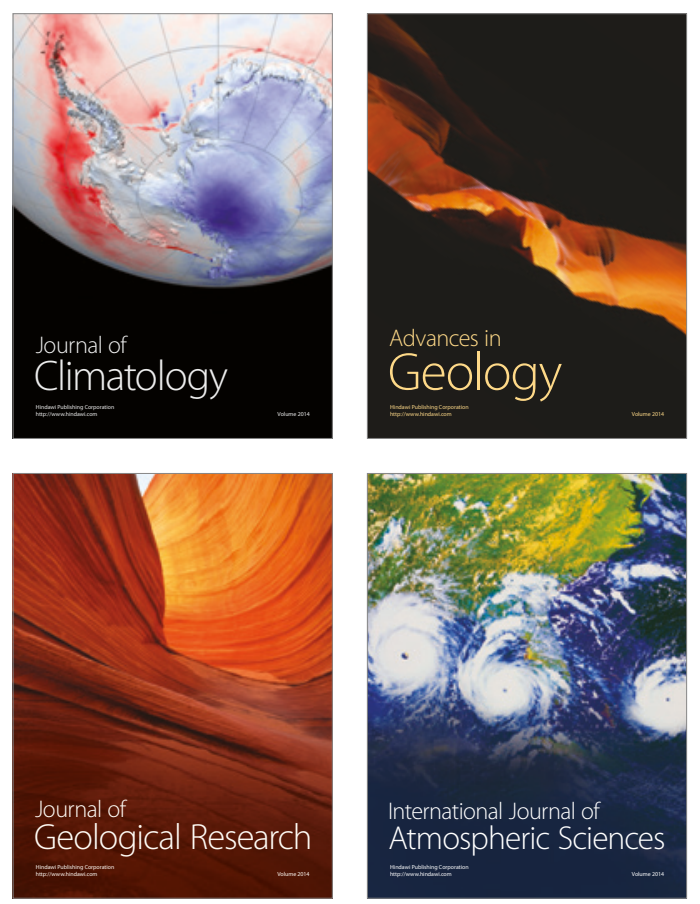

The Scientific

World Journal
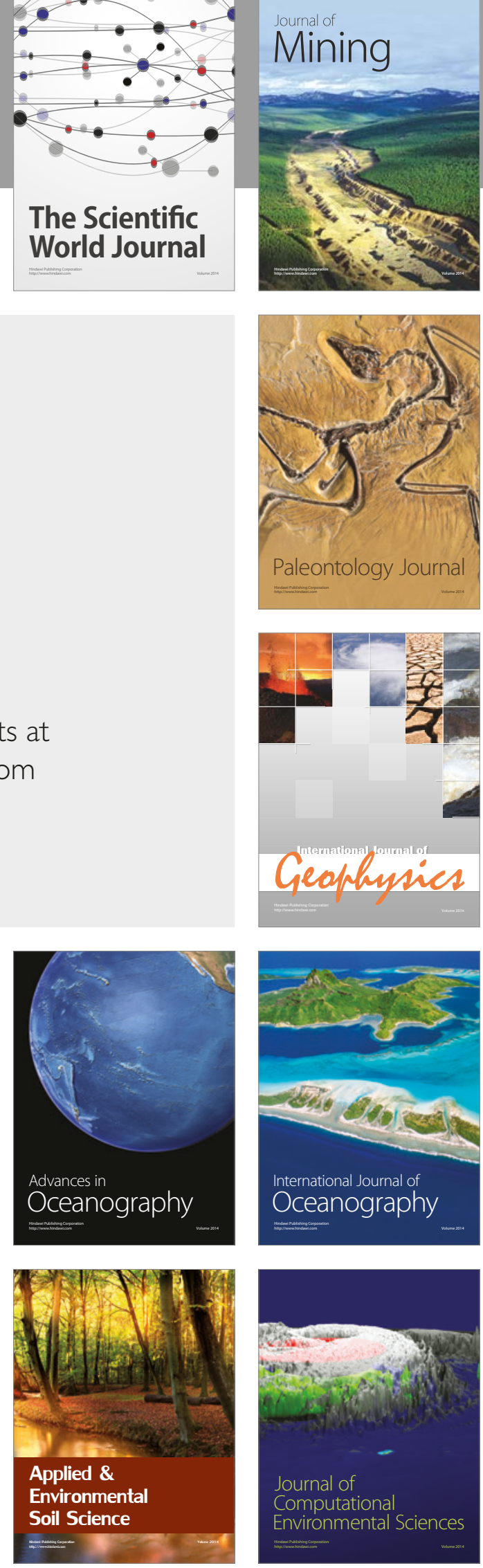